\title{
Subsidizing low-skilled jobs in a dual labor market
}

\author{
Pascal Belan \\ LEN, Université de Nantes \\ Martine Carré \\ CEPII, CREST and THEMA, Université de Cergy \\ Stéphane Gregoir*† \\ CREST-INSEE
}

May 2007

\begin{abstract}
A large exclusion from the labor market or an important unemployment of low-skilled workers is observed in some developed economies in which a minimum wage has been introduced. In such circumstances, governments may adopt two kinds of policies. They may pay unemployment benefits or they may try to increase demand for low-skilled labor by subsidizing low-skilled jobs. In this paper, we propose a matching model which allows to analyze the effects of these policies on the labor market. In our framework, the government budget is balanced through taxes on occupied workers and classical and frictional unemployment simultaneously exist. The labor market is dual featuring low-skilled and high-skilled workers. Low-skilled jobs pay the minimum wage, while high-skilled wages result from bargaining. Moreover, high-skilled unemployed can apply for both types of jobs thereby accepting to be downgraded, while opportunities for low-skilled workers are limited to low-skilled jobs. We first give conditions for the existence and uniqueness of a steadystate equilibrium and we analyze the effects of several fiscal instruments. In this set-up, increasing low-skilled job subsidies does not necessarily reduce low-skilled unemployment or unemployment spells. We provided empirical evidence by calibrating our model on French labor market data, it is found that for five low-skilled workers leaving classical unemployment, two high-skilled workers are downgraded (although they might have been previously unemployed).
\end{abstract}

Keywords: Crowding-out, Matching, On-the-job search, Taxation

JEL Classifications: H21, H23, J41

\section{Introduction}

Over the last ten years, some European countries facing a large unemployment have been implementing a mixed policy in which massive transfers to the unemployed coexist with job subsidies. Before the mid-1990s, they mainly used pure transfer policies to prevent income inequalities from rising. They switched to a mixed policy because a job subsidy strategy may allow for distributive stability and since it is less costly, given that people at work are supposed to produce something. This was the intuition of the job subsidy strategy advocated by Drèze and Malinvaud (1994) in their policy initiative for Europe, in which they recommended to finance massive low-skilled payroll tax cuts by shifting the tax burden to skilled labor. Nonetheless, in presence of classical unemployment due to a minimum wage, changing

\footnotetext{
*Address: CEPII, 9 rue Georges Pitard, 75015 Paris, France. Email: martine.carre@cepii.fr

${ }^{\dagger}$ We are thankful to J. Cimadomo, J-M. Grandmont, J-O. Hairault, G. Laroque, P. Morin, J.P. Renne and all participants to CREST, Fourgeaud (DGTPE, Ministry of Finance) and Paris I University seminars and AFSE and ASSET 2006 conferences for their comments.
} 
the fiscal scheme may change the demand but also the size and composition of the labor force. In presence of frictional unemployment in a dual labor market, increasing the fiscal burden of high skilled workers and jobs may induce changes in low-skilled and high-skilled worker job structure and in turn may be detrimental for low-skilled people situation. By introducing heterogeneous skills and possible downgrading of the high-skilled workers, we show that the effectiveness of policies aiming at reducing classical unemployment are decreasing. At the equilibrium, any additional classical unemployed reentering the job market is accompanied by an increasing number of downgraded high-skilled workers.

In practice, jobs can be characterized by the scope they offer for utilizing the worker capacities. The technology is usually such that a low-skilled job can be done by either type of workers, but a highskilled job can only be done by a high-skilled worker. As Albrecht and Vroman (2002) put it, "a Ph.D. in nuclear engineering can do rocket science or she can flip hamburger. A high-school dropout can't do rocket science but she can flip hamburger". Facing unemployment risk, some high skilled workers can accept a job that does not correspond to their level of professional qualification. For instance, Battu et al. (2000) highlight that in Britain, eleven years after graduation only $70 \%$ of graduates have a job requiring a degree. Following Hartog et al. (1994), almost $21 \%$ of high skilled workers have accepted a low-skilled position on Dutch data. In an economy where matches between high-skilled workers and low-skilled vacancies are mutually beneficial, high skilled workers take jobs away from low-skilled workers. In other words, they crowd out low-skilled workers. ${ }^{1}$ In such a situation, some people earning the same income do not have the same opportunities due to their different qualification.

Few papers discuss public policy within a dual market framework. Among them, Kleven and Sorensen (2004) and Acemoglu (2001) focus on the impact of labor market regulation on the composition of employment. The effects on the labor income distribution is explored by Lommerud et al. (2004). In contrast with these contributions, we consider an economy where workers have different skills and opportunities and in which the size of the labor force changes with the fiscal scheme. This relates our framework to papers by Cardullo and Van der Linden (2006), Pierrard (2005) and Batyra and Sneessens (2006). This last paper for instance underlines that the presence of overqualified workers plays a significant role in the relative effectiveness of low-skilled worker unemployment policies, but does not consider the role of classical unemployment.

We introduce a search model à la Pissarides that can be characterized by three key inputs : (i) an ex-ante heterogeneity of skills in workers and jobs, we distinguish low- and high-skilled workers and jobs; (ii) a productivity heterogeneity among low-skilled workers, (iii) a minimum wage for lowskilled jobs and a high-skilled wage that results from bargaining. In this dual market, we consider a situation in which classical and frictional unemployment coexist. Classical unemployment results from an heterogeneity of skills among low-skilled workers and the assumption that employees in low-skilled positions have very small negotiating power and are paid the minimum wage set by the government. Low-skilled workers are therefore in a classical unemployment situation when their output is less than the labor cost. Assuming the existence of informational asymmetries ${ }^{2}$ and the presence of frictional and classical unemployment, we illustrate the complex effects of tax wages, employment subsidies and unemployment benefits on labor market equilibrium values ${ }^{3}$.

From a theoretical point of view, two kinds of equilibria can be observed in such a framework: on

\footnotetext{
${ }^{1}$ Teulings and Koopmanschap (1989) find for example that the relative change in the employment fraction of workers with a higher level of education in occupations for which only lower education is required is higher in regions with high unemployment. They conclude then to a crowding out effect which explains the cyclical property of the unemployment rate of lower educated workers. Dolado et al. (2003) also find evidence of over-education and crowding-out effect in Europe. Finally Pierrard and Sneessens (2004) show for Belgium that the phenomenon of low skill unemployment is jointly due to relative wage rigidities, an increase in the supply of skilled labour and job competition.

${ }^{2}$ These asymetries are due to the fact that the government does not know the real opportunities of individuals. See also Hungerbuhler et al. (2003) which characterize optimal non linear income taxation in an economy with a continuum of unobservable productivity level and endogenous involuntary unemployment due to frictions in labor market.

${ }^{3}$ In a simple model of equilibrium search with wage bargaining, Pissarides (1985) shows that lump-sum negative tax wages and employment subsidies have both the same effects on employment. Both fiscal instruments reduce wages and raise employment, by rising the surplus shared. However, this result does not apply when the wage is exogenously determined, like in France. Lump-sum tax wage, employment subsidies and unemployment benefits are then three distinct instruments for government.
} 
the one hand, a segmented equilibrium in which high-skilled workers prefer to be unemployed rather than to occupy low-skilled positions. On the other hand, a cross-match equilibrium in which they prefer to be downgraded but continue to search for high-skilled positions ${ }^{4}$. In practice, the second situation is observed and we focus on it. In this set-up, efficiency of subsidy policy in favor of lowskilled jobs depends on the distribution of the heterogeneous low-skilled worker productivity and the nature of interactions on the low-skilled job market that can be decomposed into two effects : A productivity effect and a competition effect. The first one corresponds to the fact that, if we agree that high-skilled workers are generally more productive than low-skilled ones, when low-skilled positions are occupied by low-skilled and downgraded high-skilled workers, an increase in the probability of finding a high-skilled job induces a change in the composition of skills in low-skill jobs which reduces their average productivity. This negatively affects the number of low-skilled positions (vacant or not) and the probability of finding them. The second one refers to the fact that a higher probability of being employed in a high-skilled job implies a lower unemployment rate for high-skilled workers and a smaller number of applicants to low-skilled jobs which affects positively the probability of finding a lowskilled job. The two effects interact and the overall result depends on the employment/unemployment composition on job markets, the relative productivity of both types of workers and the level of taxes and subsidies. For instance, a marginal increase in taxes levied on high skill jobs may induce a decrease both in high-skilled and low-skilled jobs, or a substitution between them. In these circumstances, a change in the fiscal scheme can have non monotonous effects according to the current situation and the amplitude of the change.

Simultaneously increasing low-skilled job subsidies and high-skilled wage taxes to balance the budget may then have a reduced, possibly negative, effect on the probability to find a job for low-skilled people. The more favorable outcome of such subsidy policies in terms of low-skilled unemployment is obtained in case of a positive effect on low-skilled job firm profits and a substitution effect of highskilled jobs by low-skilled ones. But under alternative circumstances, the outcome is ambiguous and may be unfavorable to non-classical unemployed low-skilled workers. In fact, the subsidy policy widens the interval of productivity that allows for positive profits. This has a double effect: an increase in the competition between workers in order to find a job and a reduction in the expected productivity of low-skilled jobs. Subsidizing low skill jobs always diminishes classical unemployment, but at the cost of a possibly increasing of the average unemployment duration for all low-skilled workers. Moreover as subsidies get larger, reduction in low-skilled unemployment gets smaller and the number of downgraded larger. This shift of high-skilled workers to less productive positions implies that minimum unemployment and surplus maximization are incompatible in equilibrium.

This large number of high-skilled downgraded suggests that some European countries such as Belgium or France may apparently pursue contradictory objectives when they simultaneously implement active short term subsidy policies against low-skilled worker unemployment and promote policies for productivity and education in the spirit of Lisbon European conference agenda. Nevertheless, it can be noticed that the larger the high-skilled population, the less decreasing are the short term policy returns. For example, a simple calibration on French data allows us to illustrate the above mechanisms and the effects of various changes in the fiscal scheme. It appears that the level of subsidies in France induces an equilibrium in which any low-skilled worker reentering the job market is accompanied by 0.4 high-skilled worker accepting to be downgraded and that the creation of four low-skilled jobs is accompanied by the downgrading of one high-skilled worker. A possible caveat in this analysis is that we do not consider all types of fiscal reforms. We indeed do not model the motives of voluntary unemployment that may be related to heterogeneous disutilities to work. We therefore restrict our attention to changes in the fiscal scheme that leave net taxes on low-skilled workers unchanged.

The paper proceeds as follows. The setup of the model is described in the second Section. The equilibrium of the model is presented in the third one, where existence and uniqueness results are laid out. In the fourth Section we study the properties of the equilibrium and illustrate the consequences of various changes in the fiscal scheme. The fifth one is devoted to a calibration exercise on the French

\footnotetext{
${ }^{4}$ See Gautier (2002), Albrecht and Vroman (2002), Dolado et al. (2003) who consider a matching model of heterogeneous workers and jobs which includes on-the-job search for high-skilled people looking for a high-skilled job.
} 
economy. Further, the effects of a biased technological progress are analyzed by simulating a change in the productivity differential. The last Section concludes.

\section{The set-up}

We draw from the continuous-time model introduced by Albrecht and Vroman (2002) or Gautier (2002). We consider an economy consisting of a fixed labor force, modeled by a continuum of agents that can be of two exclusive types of skill : low and high. Populations of low-skilled and high-skilled people are respectively of mass $\phi_{l}$ and $\phi_{h}$. Workers are infinitely lived and assumed to be risk-neutral. On the other side of the labor market, the number of jobs is endogenous. For simplicity, we assume single worker firms, with either a simple (type $l$ ) or a complex (type $h$ ) job.

All applicants whatever their type low or high $(l$ or $h)$ can get a simple job, which needs no special skill. The technology is such that when a simple job is filled, the output produced is $s$, which is distributed between low-skilled workers on the support $[0, \bar{s}]$. Functions $x(s)$ and $X(s)$ are respectively the probability density function and the cumulative distribution function of $s$. In order to simplify the analysis, all high-skilled workers are supposed to be homogeneous in term of productivity and produce $\bar{s}$ when matching with a simple job ${ }^{5}$. At the opposite, a complex job (type $h$ ) requires a minimum skill to be productive and employers observe worker's skill when the wage bargaining starts. The output of a complex job is $s_{h}$, when the skill of worker is type $h$, and 0 otherwise. Consequently, low-skilled workers do not apply for complex jobs.

Job matchings result from a random process of search described by the following matching functions

$$
M_{i}\left(z_{i}, v_{i}\right)=\lambda_{i} z_{i}^{1-\sigma_{i}} v_{i}^{\sigma_{i}}, \lambda_{i}>0,0<\sigma_{i}<1 \text { for } i=l, h
$$

where $z_{i}$ denotes the mass of workers who applied and $v_{i}$ the mass of vacancies. The probability that an unemployed worker moves into a job $i$ is then given by $p_{i}=\lambda_{i}\left(v_{i} / z_{i}\right)^{\sigma_{i}}$, and the probability that a vacancy of type $i$ is filled, is $q_{i}=\lambda_{i}\left(z_{i} / v_{i}\right)^{1-\sigma_{i}}$. The relation between those probabilities writes

$$
q_{i}=Q_{i}\left(p_{i}\right) \equiv \lambda_{i}^{1 / \sigma_{i}} p_{i}^{1-\left(1 / \sigma_{i}\right)} \text { for } i=l, h
$$

Jobs end at the exogenous flow rate $\delta_{j}, j=l, h$. In this case, the firm becomes an unfilled vacancy and the worker becomes unemployed.

The rates at which workers find jobs are endogenous and depend not only as usual on the level of unemployment, but also on the composition of unemployment. In fact, while bargaining with a simple job supplier, a high-skilled worker may look for complex vacancies. When they accept to be downgraded, high-skilled workers impose an externality on low-skilled workers.

Real wage in the low-skilled positions is a minimum wage fixed exogenously at $\underline{w}$ by the government. We assume it smaller than $\bar{s}$, so that the productivity of high-skilled workers always cover labor cost. Nevertheless, since the support of the productivity $s$ of low-skilled workers is $[0, \bar{s}]$, the minimum wage leaves room for classical unemployment and frictions are not the only source of unemployment in this set-up. On the other hand, we assume that employees in low-skilled positions have little negotiating power and are paid the minimum wage that is set by the government at a level that ensures their accepting the jobs.

Real wages in the high-skilled sector are determined by a generalized Nash bargaining process that takes place between the individual worker and the firm, after they meet. $\beta$ is associated to high-skilled worker negotiation power. To keep the model tractable, we make the two following assumptions. (i) Search is not observable. Wolinsky (1987) and more recently Abbring (1999) show that this guarantees that workers and firms will not continue searching for similar partners during the bargaining. (ii) Following Gautier (2002), the wage is renegotiation proof, which implies that wages at complex jobs

\footnotetext{
${ }^{5}$ The main results remain unchanged if we assume some productivity heterogeneity among high-skilled workers when matching with a simple job as long as the distribution first-order dominates the low-skilled one.
} 
are independent of the workers previous labor market state. ${ }^{6}$ Under these assumptions, firms and workers negotiate a real wage $w_{h}$ which at the steady state remains constant until the job is broken up by the exogenous process assumed above.

Furthermore, we introduce a set of taxes, subsidies and benefits related to the labor market. Unemployed people receive at each period a benefit denoted by $b$. For the high-skilled workers, their wages resulting from a negotiation process, we consider a net lump-sum wage tax $\tau_{h}$. On the contrary, low-skilled worker wage being exogenously fixed, we consider a lump-sum wage tax $\tau_{l}$ paid by any worker who holds a low-skilled position and a low-skilled job tax $\kappa_{l}$ paid by the firm (both taxes can be negative). The government cannot discriminate low-skilled and high-skilled workers when they are matched with simple jobs. No information can be obtained with the observation of wages. Consequently, the government has to subsidy in the same way all simple jobs. We focus on self-financing schemes, once taken into account a fixed public good spending $(G)$.

At last, when posting a vacancy, firms face fixed costs $c_{l}$ and $c_{h}$, for simple and complex jobs respectively. They can be viewed as advertising costs. There is a free entry condition for both types of vacancies, so that, any vacancy should expect a zero expected profit at equilibrium.

We focus on equilibria in which it is beneficial for high-skilled workers to match with simple vacancies and we refer to this type as an equilibrium with cross-matching. We now write the basic Bellman equations of the model at a stationary equilibria. We do not study the path, if it exists, between two stationary equilibria related to the two sets of government instruments. This must be kept in mind, in particular regarding the interpretation of the static comparative exercises we perform in the sequel.

The discounted value of a filled $j$ job with a worker of type $i$ is denoted by $J_{i j}$ whereas the discounted value of a vacancy of type $j$ is denoted by $V_{j}$. The discounted value of a filled complex job satisfies

$$
r J_{h h}=s_{h}-w_{h}-\delta_{h}\left(J_{h h}-V_{h}\right)
$$

where $r$ is the instantaneous discount rate and $w_{h}$ is the wage paid by firms with complex jobs.

The value of a filled simple job depends on the productivity of the worker and on his opportunities. If the simple job is matched with a high-skilled worker, the value when filled is

$$
r J_{h l}=\bar{s}-\kappa_{l}-\underline{w}-\left(\delta_{l}+p_{h}\right)\left(J_{h l}-V_{l}\right)
$$

assuming that employers with filled simple jobs pay a tax $\kappa_{l}$. This equation takes into account the fact that a high-skilled worker continues to search for a complex job, and so, may quit at any moment. If a simple job is matched with a low-skilled worker, the value of the job depends on the worker's productivity $s$

$$
r J_{l l}(s)=s-\kappa_{l}-\underline{w}-\delta_{l}\left(J_{l l}(s)-V_{l}\right)
$$

Of course, a firm endowed with a simple job, matched with a low-skilled worker, accept to fill the post when surplus $J_{l l}(s)-V_{l}$ is non negative. At equilibrium, by the free-entry condition, the value of the vacancy is null. Therefore, there exists a productivity threshold, $\underline{s}=\kappa_{l}+\underline{w}$, under which firms do not accept to fill their jobs. In the following, we assume that low-skilled workers that have productivity lower than $\underline{s}$, internalize the fact that they are excluded from the job market. So doing, they no longer apply for simple jobs and constitute classical unemployment.

At the moment the vacancy is opened, employers posting a simple job do not know the type of worker they will meet. But they know the aggregate composition of unemployment and therefore can calculate the probability of meeting each of the worker type, taking into account the fact that low-skilled workers with productivity lower than $\underline{s}$ will not search for a job. We denote by $u_{h}$ the unemployment level of high-skilled workers and by $u_{l}(s)$ the unemployment level of low-skilled workers with productivity $s$. Since we assume that it is profitable to high-skilled workers to accept low-skilled

\footnotetext{
${ }^{6}$ As Gautier (2002) explains, the intuition is the following. If an employed worker would use his simple-job-wage as threat point in the bargaining, firms would initially agree but then re-open the bargaining at the moment the worker actually quits. In the new bargaining, the worker's outside option is similar to the outside option of an unemployed worker.
} 
positions, we have

$$
r V_{l}=-c_{l}+q_{l}\left(\frac{\int_{\underline{s}}^{\bar{s}} u_{l}(s) J_{l l}(s) d s+u_{h} J_{h l}}{\int_{\underline{s}}^{\bar{s}} u_{l}(s) d s+u_{h}}-V_{l}\right)
$$

where $c_{l}$ is a fixed cost paid by firms when posting a vacancy for a simple job. It can be viewed as an advertising cost. At last, for complex jobs,

$$
r V_{h}=-c_{h}+q_{h}\left(J_{h h}-V_{h}\right)
$$

where $c_{h}$ is the fixed cost paid by firms which offer complex jobs.

We now turn to workers' discounted values. The low-skilled workers which are below the threshold of productivity $\underline{s}$ and are consequently excluded from the job market, will receive the grant $b$. The corresponding value $U_{l}^{e}$ satisfies

$$
r U_{l}^{e}=b
$$

For other workers, let $U_{i}$ and $N_{i j}$ be respectively the discounted values of being unemployed and employed, where $i=l, h$ denotes the skill of the worker, and $j=l, h$ the type of the job. At steady state, $U_{l}$ satisfies

$$
r U_{l}=b+p_{l}\left(N_{l l}-U_{l}\right)
$$

Since the minimum wage applies to all simple jobs, the discounted values $N_{l l}$ and $U_{l}$ do not depend on the productivity $s$ of the worker under consideration. ${ }^{7}$

When accepting a low-skilled job is profitable, the discounted value of being unemployed for a high-skilled individual satisfies

$$
r U_{h}=b+p_{l}\left(N_{h l}-U_{h}\right)+p_{h}\left(N_{h h}-U_{h}\right)
$$

In the low-skilled sector, discounted value of a low-skilled employed worker writes

$$
r N_{l l}=\underline{w}-\tau_{l}-\delta_{l}\left(N_{l l}-U_{l}\right)
$$

and, assuming that $N_{h h}$ is always at least as large as $N_{h l}$, we get

$$
r N_{h h}=w_{h}-\tau_{h}-\delta_{h}\left(N_{h h}-U_{h}\right)
$$

Discounted value of simple job for a high-skilled worker satisfies ${ }^{8}$

$$
r N_{h l}=\underline{w}-\tau_{l}-\delta_{l}\left(N_{h l}-U_{h}\right)+p_{h}\left(N_{h h}-N_{h l}\right)
$$

\footnotetext{
${ }^{7}$ Note that, in this model, the search cost is null. Then, people are indifferent between staying at home or searching without success. We consider in this case that, knowing the fact that they cannot be successful in their search on the job market, they do not search, and, then, do not increase job market frictions. With positive search cost, equation (8) should be rewritten as

$$
r U_{l}=b-c_{r}+p_{l}\left(N_{l l}-U_{l}\right) .
$$

and a low-skilled unemployed which can potentially find a job may be incited to mimic an excluded one. $p_{l}$ being endogenous, we have to face an indeterminacy of the equilibrium. The equilibrium depends on the belief of each agent on the behavior of the others and winds up with a coordination problem between low-skilled workers. Keeping to a simple analysis that enhances the consequences of interactions between the two sources of unemployment, we assume that $c_{r}=0$.

${ }^{8} \mathrm{~A}$ possible extension would be to introduce some disutility of being downgraded for a high-skilled worker, by adding a constant $\rho_{h l}\left(\rho_{h l} \geq 0\right)$ in the expression of the discounted value of a simple job for a high-skilled worker

$$
r N_{h l}=\underline{w}-\tau_{l}-\rho_{h l}-\delta_{l}\left(N_{h l}-U_{h}\right)+p_{h}\left(N_{h h}-N_{h l}\right)
$$

The parameter $\rho_{h l}$ would represent the fact that a wage relation encompasses an economic and social relation, and that the social status procured by a job is not the least important aspect of the wage relation (see for instance on this subject Solow (1990)). Introducing disutility of being downgraded could sharply modify the nature of the equilibrium since high-skilled workers may be willing to only apply for complex jobs, whereas low-skilled workers apply to low-skilled jobs, leading to ex-post segmentation.
} 
Figure 1: Flows chart

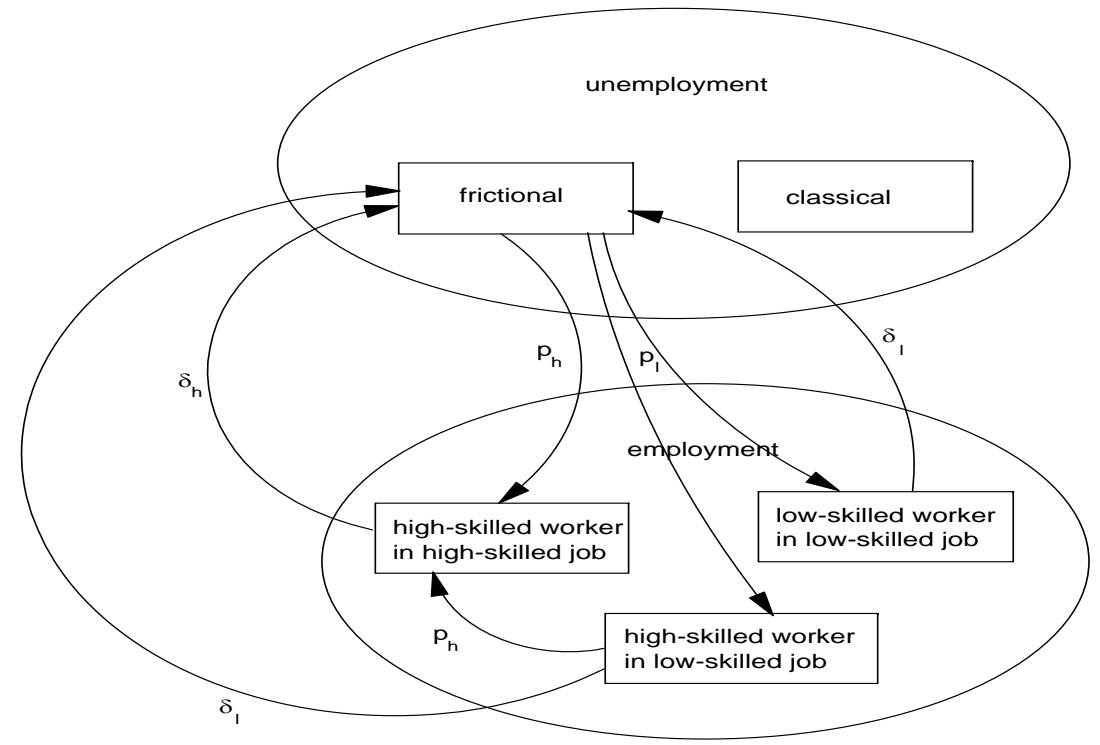

Figure 1 summarizes the flows of job creation and destruction involved in the modeling.

Finally, the wage rate negotiated after the Nash bargain may be derived from the maximization of the function:

$$
\left[N_{h h}-U_{h}\right]^{\beta}\left[J_{h h}-V_{h}\right]^{1-\beta}
$$

which implies,

$$
\beta\left(J_{h h}-V_{h}\right)=(1-\beta)\left(N_{h h}-U_{h}\right)
$$

\section{Definition and existence of equilibrium}

We focus on cross-matching equilibria such that

$$
N_{l l} \geq U_{l} \quad N_{h h} \geq N_{h l} \geq U_{h}
$$

So doing, we exclude equilibria where low and high-skilled workers choose to remain unemployed, despite their productivity parameter is high enough for being hired. Similarly, we do not consider situations where fiscal incentives lead high-skilled workers to prefer to work in simple jobs rather than complex jobs, and continue to apply for simple jobs when they are matched with a complex one. As the following lemma states, inequalities $N_{l l} \geq U_{l}$ and $N_{h l} \geq U_{h}$ depends crucially on fiscal instruments

Lemma 1 High-skilled workers and low-skilled workers apply for simple jobs if and only if $\tau_{l}+b \leq \underline{w}$.

Proof. From equations (8), (9), (10) and (13), we have

$$
N_{h l}-U_{h}=\frac{\underline{w}-\tau_{l}-b}{r+\delta_{l}+p_{l}+p_{h}}
$$

and

$$
N_{l l}-U_{l}=\frac{\underline{w}-\tau_{l}-b}{r+\delta_{l}+p_{l}}
$$

that leads to the result. 
From Bellman equations, straightforward calculations show that the equilibrium values of arrival rates, high-skilled wage, unemployment levels and employment levels only depend on $\kappa_{l}, \tau_{l}+b$ and $\tau_{h}+b$. The equilibrium value of the grant $b$ then results from the government budget constraint

$$
G+\left(\phi_{l} X(\underline{s})+\int_{\underline{s}}^{\bar{s}} u_{l}(s) d s+u_{h}\right) b=\left(\int_{\underline{s}}^{\bar{s}} e_{l l}(s) d s+e_{h l}\right)\left(\tau_{l}+\kappa_{l}\right)+e_{h h} \tau_{h}
$$

where $G$ represents government spending, $\phi_{l} X(\underline{s})$ is the mass of excluded workers, $u_{l}(s)$ and $e_{l l}(s)$ are unemployment and employment levels of type-s low-skilled workers, $u_{h}$ is unemployment level of high-skilled workers and $e_{h j}$ is their employment level in type- $j$ jobs. Indeed, rewriting this constraint as

$$
\left(\phi_{l}+\phi_{h}\right) b=\left(\int_{\underline{s}}^{\bar{s}} e_{l l}(s) d s+e_{h l}\right)\left(\tau_{l}+b+\kappa_{l}\right)+e_{h h}\left(\tau_{h}+b\right)-G
$$

allows us to compute the equilibrium level of $b$ that corresponds to particular values of $\kappa_{l}, \tau_{l}+b$ and $\tau_{h}+b$. Then, one obtains the taxes levels $\tau_{l}$ and $\tau_{h}$ by subtracting $b$ to the levels of $\tau_{l}+b$ and $\tau_{h}+b$ chosen by the government. We summarize this process in the following assumption.

Assumption 1 The government announces instruments values $\left(\tau_{l}, \tau_{h}, b, \kappa_{l}\right)$ such that $\tau_{l}+b \leq \underline{w}$, $\tau_{h}+b<s_{h}, \kappa_{l}<\bar{s}-\underline{w}$ and satisfying the government budget constraint for equilibrium values of unemployment and employment levels.

An important characteristic of our setup is that the structure of unemployment matters for the determination of equilibrium arrival rates. Indeed, a high-skilled worker may leave a simple job at any time if he is matched with a complex one. Thus, the separation rate of a high-skilled worker is $\delta_{l}+p_{h}$, while the separation rate of a low skilled one is always $\delta_{l}$. Then, a simple job filled with a high-skilled worker has a lower value than a simple job filled with a low-skilled worker with the same productivity, i.e. $\bar{s}$. Moreover, the expected value of vacant simple jobs is also affected by the distribution of productivity among low-skilled unemployed. The more they are concentrated around $\bar{s}$, the larger this expected value will be. Consequently, equilibrium arrival rates and unemployment levels are determined simultaneously.

Definition 1 Given $\left(\tau_{l}, \tau_{h}, b, \kappa_{l}\right)$ satisfying Assumption 1, a steady-state equilibrium consists of nonnegative arrival rates $\left(p_{i}, q_{i}\right)_{i \in\{l, h\}}$, workers and job values $\left(U_{i}, V_{i}\right)_{i \in\{l, h\}},\left(N_{a}, J_{a}\right)_{a \in\{l l, h l, h h\}}$, high-skilled wages $w_{h}$ and unemployment levels $\left(u_{l}(s)\right)_{s \in[\underline{s}, \bar{s}]}$ and $u_{h}$ characterized by

- Bellman equations for firms (2), (3), (4), (5), (6),

- Bellman equations for workers (8), (9), (10), (11), (13),

- wage bargaining equation (14),

- unemployment levels resulting from flow equilibria (see Appendix B)

$$
u_{l}(s)=\phi_{l} x(s) \frac{\delta_{l}}{\delta_{l}+p_{l}} \text { and } u_{h}=\phi_{h} \frac{\delta_{h}}{\delta_{h}+p_{h}} \frac{\delta_{l}+p_{h}}{\delta_{l}+p_{h}+p_{l}},
$$

and satisfying the inequality $N_{h h} \geq N_{h l}$.

We first state the range of values of the arrival rate $p_{h}$ that correspond to positive arrival rate $p_{l}$ and that satisfy $N_{h h} \geq N_{h l} \geq U_{h}$. We need the following assumption.

Assumption 2 Instruments values $\left(\tau_{l}, \tau_{h}\right)$ and parameters satisfy either (i) $s_{h}-\tau_{h}<\underline{w}-\tau_{l}$ and $r+\delta_{h} \leq \beta\left(r+\delta_{l}\right)$ or (ii) $s_{h}-\tau_{h} \geq \underline{w}-\tau_{l}$. 
Proposition 1 Let $\left(\tau_{l}, \tau_{h}, b, \kappa_{l}\right)$ satisfying Assumptions 1 and 2. If a steady-state equilibrium exists, the equilibrium arrival rate $p_{h}$ belongs to a non-empty interval $\left[\underline{p}_{h}, \bar{p}_{h}\right]$ where $\underline{p}_{h}$ and $\bar{p}_{h}$ are defined by the following inequalities

$$
\begin{aligned}
\left(s_{h}-\tau_{h}-b\right)-\left(\underline{w}-\tau_{l}-b\right) & \leq \frac{\left(r+\delta_{h}+\beta p_{h}\right) c_{h}}{(1-\beta) Q_{h}\left(p_{h}\right)} \leq s_{h}-\tau_{h}-b \\
\frac{\left(r+\delta_{h}-\beta\left(r+\delta_{l}\right)\right) c_{h}}{(1-\beta) Q_{h}\left(p_{h}\right)} & \leq\left(s_{h}-\tau_{h}-b\right)-\left(\underline{w}-\tau_{l}-b\right) \\
p_{h} & \geq 0
\end{aligned}
$$

Proof. From (2), (6), (9), (11), (13) and (14) and the free-entry condition $V_{h}=0$, we get

$$
\left(r+\delta_{h}+\beta p_{h}\right) \frac{c_{h}}{(1-\beta) q_{h}}=\left(s_{h}-\tau_{h}-b\right)-\frac{p_{l}}{r+\delta_{l}+p_{l}+p_{h}}\left(\underline{w}-\tau_{l}-b\right)
$$

If $\underline{w}=\tau_{l}+b$, this equation determines $p_{h}$ which satisfies inequalities (17), (18) and (19). If $\underline{w}>\tau_{l}+b$, equation (20) can be rewritten as

$$
\begin{aligned}
p_{l} & =P_{l}\left(p_{h}, \tau_{l}+b, \tau_{h}+b\right) \\
& \equiv\left(r+\delta_{l}+p_{h}\right) \frac{\left(s_{h}-\tau_{h}-b\right)-\frac{\left(r+\delta_{h}+\beta p_{h}\right) c_{h}}{(1-\beta) Q_{h}\left(p_{h}\right)}}{\frac{\left(r+\delta_{h}+\beta p_{h}\right) c_{h}}{(1-\beta) Q_{h}\left(p_{h}\right)}-\left[\left(s_{h}-\tau_{h}-b\right)-\left(\underline{w}-\tau_{l}-b\right)\right]}
\end{aligned}
$$

For positive $p_{h}$, the arrival rate for low-skilled workers $p_{l}$ is positive if the numerator and the denominator in $P_{l}$ are both positive. This leads to inequality (17).

Moreover, from equations (2), (6), (9), (11), (13) and (14) and the free-entry condition $V_{h}=0$, the condition $N_{h h} \geq N_{h l}$ is equivalent to

$$
\beta\left(r+\delta_{l}+p_{l}+p_{h}\right) \frac{s_{h}-\tau_{h}-b}{\underline{w}-\tau_{l}-b} \geq\left(r+\delta_{h}+\beta\left(p_{l}+p_{h}\right)\right)
$$

which, replacing $p_{l}$ by the expression of $P_{l}$, leads to inequality (18). To conclude the proof, one has to notice that the combination of the inequalities (17), (18) and (19) define a convex interval of values of $p_{h}$.

Boundaries $p_{h}$ and $\bar{p}_{h}$ are not always defined by the same inequality. This depends on the sign of $r+\delta_{h}-\beta\left(r+\delta_{l}\right)$ and $\left(s_{h}-\tau_{h}\right)-\left(\underline{w}-\tau_{l}\right)$. The case $\left\{s_{h}-\tau_{h}<\underline{w}-\tau_{l}\right.$ and $\left.r+\delta_{h}-\beta\left(r+\delta_{l}\right)>0\right\}$ leads to an empty interval, since inequality (18) would never be satisfied. In any other case, the interval $\left[\underline{p}_{h}, \bar{p}_{h}\right]$ is non-empty (details are given in appendix $\mathrm{B}$ ).

From (3), (4), (5), the free-entry condition $V_{l}=0$ and $\underline{s}=\kappa_{l}+\underline{w}$, we obtain

$$
c_{l}=q_{l} \frac{\frac{\delta_{l} \phi_{l}\left(1-X\left(\kappa_{l}+\underline{w}\right)\right)}{\delta_{l}+p_{l}} \int_{\kappa_{l}+\underline{w}}^{\bar{s}} \frac{s-\kappa_{l}-\underline{w}}{r+\delta_{l}} \frac{x(s) d s}{1-X\left(\kappa_{l}+\underline{w}\right)}+u_{h} \frac{\bar{s}-\kappa_{l}-\underline{w}}{r+\delta_{l}+p_{h}}}{\frac{\delta_{l} \phi_{l}\left(1-X\left(\kappa_{l}+\underline{w}\right)\right)}{\delta_{l}+p_{l}}+u_{h}}
$$

which is equivalent to

$$
\frac{Q_{l}\left(p_{l}\right)}{r+\delta_{l}+p_{h}} \frac{\left(1+\frac{p_{h}}{r+\delta_{l}}\right) B\left(\kappa_{l}\right)+\gamma}{1+\gamma}-\frac{c_{l}}{\bar{s}-\kappa_{l}-\underline{w}}=0
$$

where

$$
\begin{gathered}
\gamma=\frac{\phi_{h}}{\left(1-X\left(\kappa_{l}+\underline{w}\right)\right) \phi_{l}} \frac{\delta_{h}}{\delta_{l}} \frac{\delta_{l}+p_{h}}{\delta_{h}+p_{h}} \frac{\delta_{l}+p_{l}}{\delta_{l}+p_{l}+p_{h}}, \\
B\left(\kappa_{l}\right)=\int_{\kappa_{l}+\underline{w}}^{\bar{s}} \frac{s-\kappa_{l}-\underline{w}}{\bar{s}-\kappa_{l}-\underline{w}} \frac{x(s) d s}{1-X\left(\kappa_{l}+\underline{w}\right)}<1 .
\end{gathered}
$$


Notice that $B\left(\kappa_{l}\right)=1$, if all low-skilled workers have productivity $\bar{s}$.

If $\tau_{l}+b=\underline{w}$, then the arrival rate $p_{h}$ is the solution of equation (20) and $p_{l}$ is the unique positive solution of equation (22) (since the LHS is decreasing from $+\infty$ to $-c_{l} /\left(s_{l}-\kappa_{l}-\underline{w}\right.$ ) when $p_{l}$ increases from 0 to $+\infty)$.

Now, if $\tau_{l}+b<\underline{w}$, equation (22) rewrites, using (21),

$$
H\left(p_{h}, \kappa_{l}, \tau_{l}+b, \tau_{h}+b\right)=0 .
$$

In general, there may exist zero or more than one equilibrium. Nevertheless, it is possible to state conditions for existence and uniqueness. We proceed in two steps. First, we state existence and uniqueness when the productivity parameter is $\bar{s}$ for all low-skilled workers. Second, we release this assumption and give conditions for existence and uniqueness when $s$ is distributed on $[0, \bar{s}]$ according to the density function $x(s)$. In the first case, we have $B\left(\kappa_{l}\right)=1$, while, in the second case $B\left(\kappa_{l}\right)<1$.

Proposition 2 Let $\left(\tau_{l}, \tau_{h}, b, \kappa_{l}\right)$ satisfying Assumptions 1 and 2. Suppose that the productivity parameter is $\bar{s}$ for all low-skilled workers $\left(B\left(\kappa_{l}\right)=1\right)$. If

$$
\sigma_{l}+\sigma_{h} \leq 1 \text { and } \delta_{l} \geq \delta_{h},
$$

the function $H$ is increasing with respect to $p_{h}$ on the interval $\left[\underline{p}_{h}, \bar{p}_{h}\right]$. If, in addition,

$$
H\left(\underline{p}_{h}, \kappa_{l}, \tau_{l}+b, \tau_{h}+b\right)<0
$$

then there exists a unique cross-matching equilibrium in which the arrival rate for high-skilled workers is denoted $p_{h}^{*}$.

Proof. Existence directly results from (24) and uniqueness is a consequence of Lemma 2 in Appendix B.

Proposition 3 Let $\left(\tau_{l}, \tau_{h}, b, \kappa_{l}\right)$ satisfying Assumptions 1 and 2. Suppose that conditions (23) and (24) in Proposition 2 hold. If

$$
B\left(\kappa_{l}\right)>\frac{r+\delta_{l}}{r+\delta_{l}+p_{h}^{*}}, \text { for all } \kappa_{l} \in[-\underline{w}, \bar{s}-\underline{w}],
$$

then there exists a unique cross-matching equilibrium. Moreover, $p_{h}$ increases with respect to $\tau_{l}+b$ and $\kappa_{l}$ and decreases with respect to $\tau_{h}+b$.

Proof. Note that $H\left(p_{h}, \kappa_{l}, \tau_{l}+b, \tau_{h}+b\right)$ shifts downward when $B\left(\kappa_{l}\right)$ diminishes. By consequence, there exists an equilibrium. It remains to show that the condition $B\left(\kappa_{l}\right)>\frac{r+\delta_{l}}{r+\delta_{l}+p_{h}^{*}}$ implies uniqueness. We proceed by stating that, under this condition,

$$
B\left(\kappa_{l}\right)>\frac{r+\delta_{l}}{r+\delta_{l}+p_{h}}
$$

which implies $\frac{\partial H}{\partial p_{h}}>0$ and thus that the equilibrium is unique. Since $H$ is shifted downward, the new equilibrium arrival rate $p_{h}$ (with $B<1$ ) is higher than $p_{h}^{*}$. Thus

$$
B\left(\kappa_{l}\right)>\frac{r+\delta_{l}}{r+\delta_{l}+p_{h}^{*}}>\frac{r+\delta_{l}}{r+\delta_{l}+p_{h}}
$$

which states uniqueness.

Moreover $P_{l}\left(p_{h}, \tau_{l}+b, \tau_{h}+b\right)$ is increasing (decreasing) with respect to its second (third) argument. Since, an increase in $p_{l}$ has a negative effect on the LHS in (22), the function $H$ is increasing (decreasing) with respect to $\tau_{l}+b$ (resp. $\left.\tau_{h}+b\right)$ ). Finally, $H$ is decreasing with respect to $\kappa_{l}$. This concludes the proof. 


\section{Equilibrium properties}

In order to avoid useless complexity, we assume $\sigma_{l}=\sigma_{h}=1 / 2$ and $\delta_{l} \geq \delta_{h}$. Rearranging equation (22), we obtain:

$$
\begin{array}{r}
\left(\frac{p_{l}}{p_{l}^{s}\left(\kappa_{l}\right)}-\frac{1}{B\left(\kappa_{l}\right)} \frac{r+\delta_{l}}{r+\delta_{l}+p_{h}}\right)\left[1+\frac{\phi_{h}}{\left(1-X\left(\kappa_{l}+\underline{w}\right)\right) \phi_{l}} \frac{\delta_{h}}{\delta_{l}} \frac{\delta_{l}+p_{h}}{\delta_{h}+p_{h}} \frac{\delta_{l}+p_{l}}{\delta_{l}+p_{l}+p_{h}}\right] \\
=1-\frac{1}{B\left(\kappa_{l}\right)} \frac{r+\delta_{l}}{r+\delta_{l}+p_{h}}
\end{array}
$$

with

$$
p_{l}^{s}\left(\kappa_{l}\right) \equiv B\left(\kappa_{l}\right) \frac{\lambda_{l}^{2}}{c_{l}} \frac{\left(\bar{s}-\kappa_{l}-\underline{w}\right)}{r+\delta_{l}}
$$

The level $p_{l}^{s}\left(\kappa_{l}\right)$ corresponds to the arrival rate of simple jobs if no high-skilled worker were posting for a low-skilled job. For a given arrival rate $p_{h}$, we obtain a polynomial of degree two in $p_{l}$ whose solutions are given in Appendix. We select the solution $p_{l, l}^{c}\left(p_{h}\right)$ that satisfies the condition

$$
p_{l, l}^{c}\left(\left(\frac{1}{B\left(\kappa_{l}\right)}-1\right)\left(r+\delta_{l}\right)\right)=p_{l}^{s}\left(\kappa_{l}\right)
$$

and is positive. It is a continuous function such that $\lim _{p_{h} \rightarrow \infty} p_{l, l}^{c}\left(p_{h}\right)=p_{l}^{s}\left(\kappa_{l}\right)$. We plot this relation between $p_{l}$ and $p_{h}$ in Figure 2 (low-skilled job market curve). On the other hand from (21), we have

$$
p_{l, h}^{c}\left(p_{h}\right)=\frac{\left(r+\delta_{l}+p_{h}\right)\left(s_{h}-\tau_{h}-b-\frac{c_{h}\left(r+\delta_{h}+\beta p_{h}\right) p_{h}}{(1-\beta) \lambda_{h}^{2}}\right)}{\frac{c_{h}\left(r+\delta_{h}+\beta p_{h}\right) p_{h}}{(1-\beta) \lambda_{h}^{2}}-\left[\left(s_{h}-\tau_{h}-b\right)-\left(\underline{w}-\tau_{l}-b\right)\right]}
$$

which is a decreasing function of $p_{h}$ that is positive for $\underline{p}_{h}<p_{h}<\bar{p}_{h}$ expression of which are given in Appendix. We also plot this relation in Figure 2 (high-skilled job market curve).

The steady-state equilibrium corresponds in Figure 2 to the intersection of the curves (1) and (2) that respectively represent the free-entry conditions in the high-skilled sector and in the low-skilled one. In Figure 2, the two curves intersect at $\mathrm{E}$ in the decreasing part of the low-skilled curve. In this sense, $p_{h}$ and $p_{l}$ can be viewed as "substitutes". A small shift of the high-skilled curve implies an opposite sign change in the two categories. Conversely, in an economy where the two curves intersect in E' on the increasing part of the low-skilled curve ((1') and (2)), $p_{h}$ and $p_{l}$ can be viewed as "complementary". Consequently, a small increase in $p_{h}$ can be associated to an increase in $p_{l}$. Interactions between highskilled and low-skilled workers on low-skilled job market allow to explain the U-shape of the free-entry condition on this market. On the one hand, an increase in $p_{h}$ enhances the probability for high-skilled workers to find more suitable job for them. Consequently, job turnover of simple jobs increases, which leads to a decrease in the average value of filled simple job. This effect, that we call the productivity effect, reduces $p_{l}$. On the other hand, an increase in $p_{h}$ reduces high-skilled workers unemployment spell. Increasing $p_{h}$ modifies consequently the aggregate composition of unemployed workers. The probability of hiring a high-skilled worker decreases for simple jobs. The simple job market moves closer to the segmented equilibrium, where only low-skilled workers look for simple jobs. This effect, that we call the competition effect, increases $p_{l}$. When $p_{h}$ is initially relatively high, the unemployment rate is very low for high-skilled people, the competition effect dominates, while for low values of $p_{h}$, the productivity effect dominates. In Figure 2, we have plotted the frontier (3) between complementarity and substituability regimes.

We now turn to the effect of the fiscal instruments $\left(\kappa_{l}, \tau_{l}, \tau_{h}, b\right)$. They work differently on the two free-entry conditions. The low-skilled job tax $\kappa_{l}$ affects only the position of the low-skilled curve, whereas other instruments affect the high-skilled curve.

A marginal increase in $b$ enhances the outside opportunity of high-skilled workers in the wage bargaining. This leads to a rise in $w_{h}$ and, consequently, a fall in the mass of complex jobs through the 
Figure 2: Change in equilibrium related to a change in $\tau_{h}$

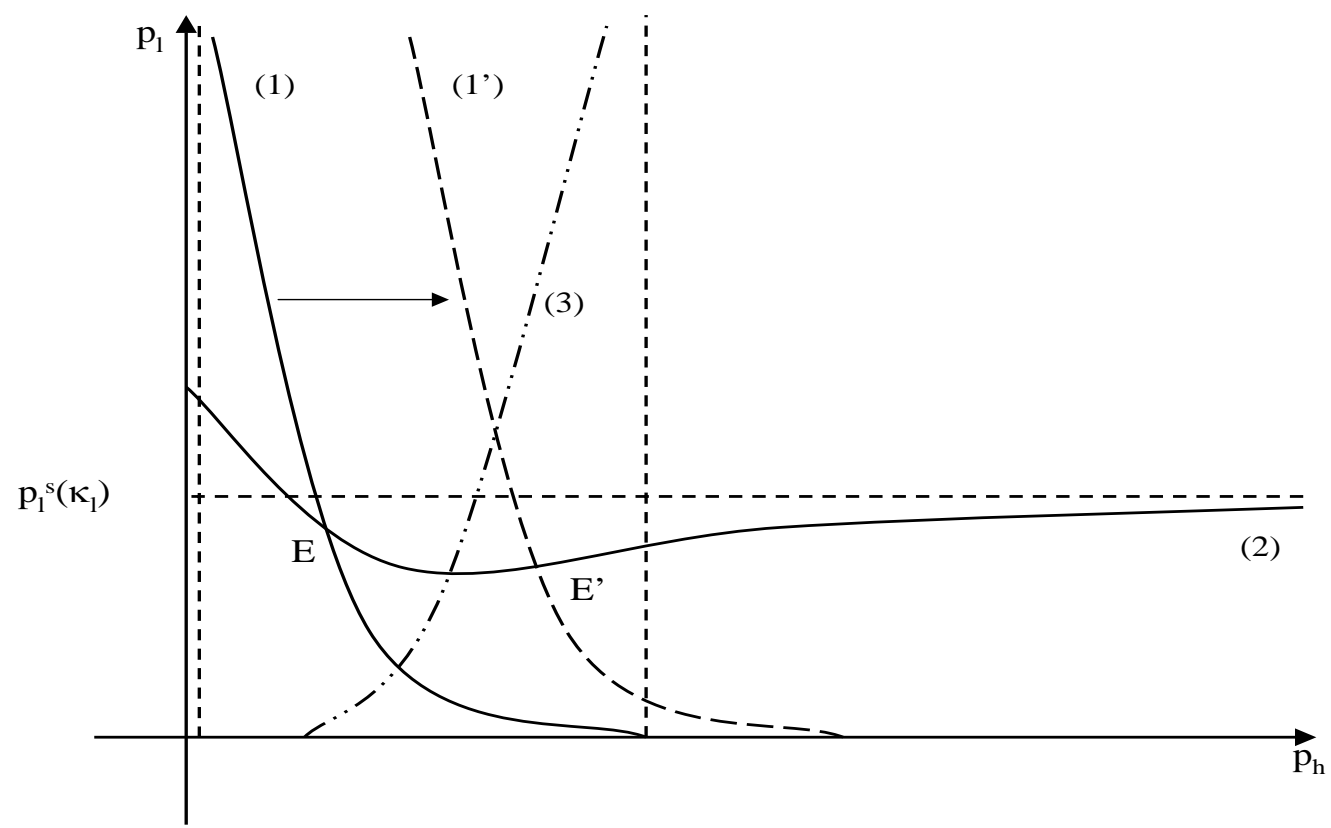

Figure 3: Example of a change in equilibrium related to a change in $\kappa_{l}$

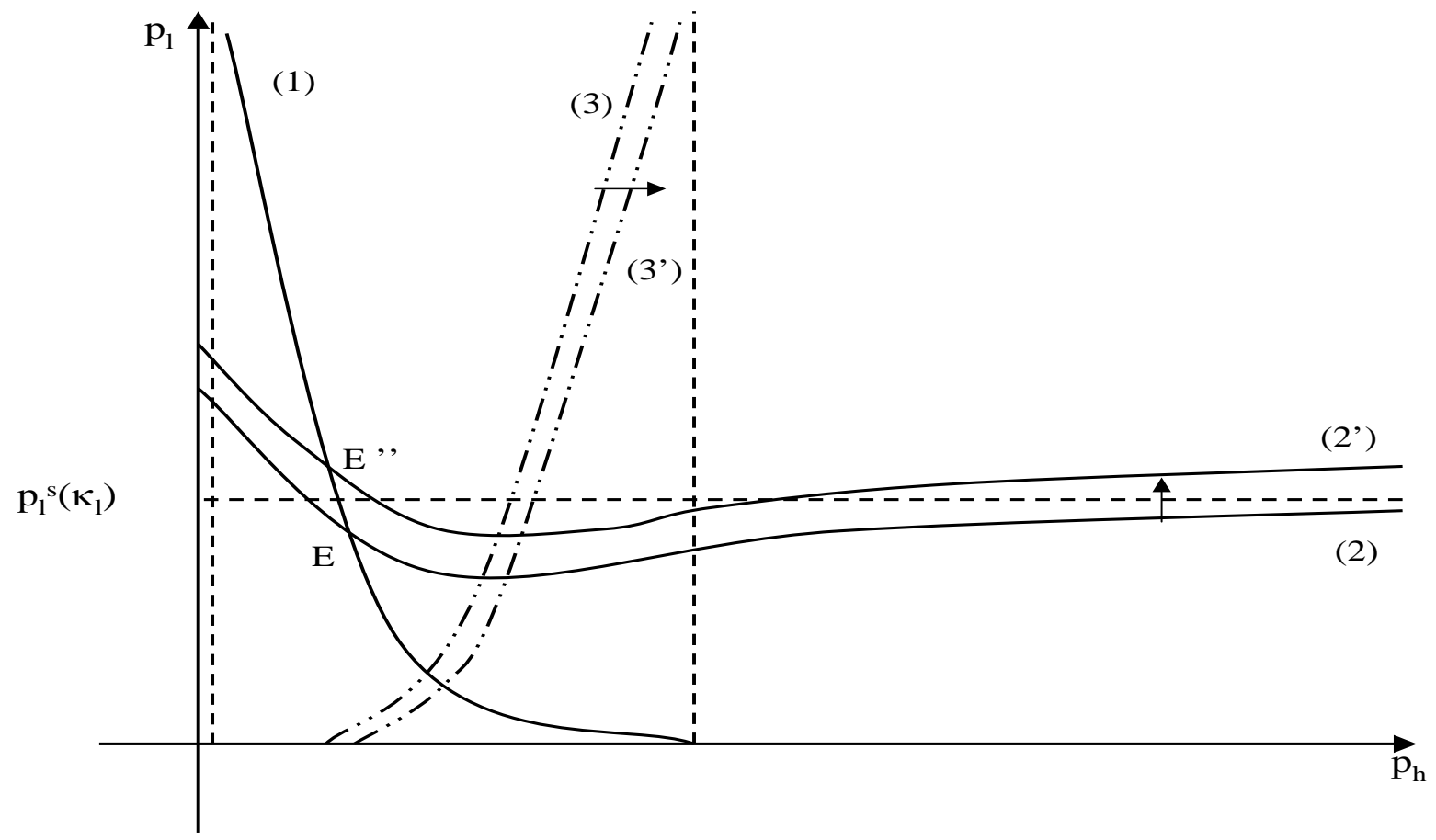


free-entry condition. We then observe a decrease in $p_{h}$. Depending on whether the initial level of $p_{h}$ belongs to the complementarity or substituability regime, the resulting effect on $p_{l}$ may be respectively negative or positive. An increase in the $\operatorname{tax} \tau_{h}$ is shared between the firm and the workers because of the wage bargaining. Here again, the wage $w_{h}$ increases and one observes the same qualitative changes in $p_{h}$ and $p_{l}$. An increase in $\tau_{l}$ has also no effect on the low-skilled curve, since there is no bargaining on simple jobs. Nevertheless, a higher tax $\tau_{l}$ means that low-skilled jobs become less attractive for high-skilled workers, weakening their outside opportunity in the wage bargaining on $w_{h}$. This results in a higher arrival rate $p_{h}$.

Let us now turn to a decrease in $\kappa_{l}$, the policy that we focus on. For a given $p_{h}$, this may have contradictory effects on low-skilled unemployment. The fall in $\kappa_{l}$ reduces the cost of simple jobs. It contributes positively to profits generated by these jobs, which tends to increase the number of lowskilled job firms and affects positively $p_{l}$. This allows unemployed high-skilled workers to find some downgraded positions. Simultaneously, it lowers the productivity threshold of positive profit. This implies that some low-skilled workers can re-enter the job market. Classical unemployment will then be reduced. But the widening of the interval of productivity that allows for positive profits also has a double effect: an increase in the competition between workers in order to find a job and a reduction in the expected productivity of low-skilled jobs. Both effects decrease $p_{l}$ and contradict the first effect. Summarizing these results, a decrease in $\kappa_{l}$ allows for a reduction in classical unemployment and has an ambiguous effect on $p_{l}$, i.e. the average duration of low-skilled vacancies and of low-skilled frictional unemployment. Graphically, the ambiguous effect on $p_{l}$ means that the low-skilled curve may shift upward or downward depending on the relative importance of the contradictory effects.

From the above discussion, when the change in $p_{l}$ is positive, we wind up with a decrease in low-skilled unemployment. When negative, the average decrease in low-skilled job productivity may induce an increase in the frictional low-skilled unemployment $\left(u_{l, f}\right)$ that may dominate the reduction of classical unemployment $\left(u_{l, c}\right)$. But if the fall in average low-skilled job productivity remains moderate, the decrease in $\kappa_{l}$ would result in an decrease in $p_{l}$, allowing nevertheless for a lower low-skilled unemployment $u_{l, c}+u_{l, f}$. This would be associated to longer frictional unemployment spells.

The consequences of the above mechanisms on $p_{h}$ when, for instance, $p_{l}$ increases are quite simple: change in $p_{h}$ is negative since high-skilled workers have now a better outside opportunity and can claim for higher wages $w_{h}$. Notice that the fall in $p_{h}$, in turn, increases the number of downgraded highskilled workers (see equations (29) in Appendix B) and contributes to a higher average productivity of low-skilled jobs.

We are now able to describe the consequences of balanced-budget fiscal policies that consist in subsidizing low-skilled jobs. We only focus on a financing scheme that amounts to an increase in taxes on high-skilled jobs $\tau_{h}$. Reducing unemployment benefits $b$ is an alternative scheme we do not consider because it can affect voluntary unemployment we do not model. Such policies imply shifts of the two free-entry conditions. Let us assume that a fall in $\kappa_{l}$ shifts upward the free-entry condition for low-skilled jobs and increases the arrival rate $p_{l}$ for any given value of $p_{h}$, as plotted in Figure 3 . The direct consequence of the upward shift of the low-skilled free-entry condition is to increase $p_{l}$ and reduce $p_{h}$. Therefore, the number of filled simple jobs $e_{l l}+e_{h l}$ rises, while the number of filled complex jobs $e_{h h}$ falls (see equations (29) in Appendix B). The overall decreasing number of unemployed people reduces the burden of unemployment benefits but this may not offset the cost of the subsidy policy that applied to every low-skilled position. This may lead to some budget deficit that can be compensated by an increase in $\tau_{h}$. Combining Figures 2 and 3, we can picture the situation in which resources that finance the subsidy are levied through an increase in the tax on high-skilled jobs $\tau_{h}$. The change in $\tau_{h}$ shifts the high-skilled free-entry condition to the left, leading to a lower arrival rate on high-skilled job $p_{h}$. Increasing high-skilled job taxes affects negatively the number of high-skilled jobs. Due to high-skilled worker bargaining power, tax increase is shared between the firms and the workers. This increases the frictional high-skilled worker unemployment and the burden of unemployment benefits. This effect is nevertheless limited by an increase in the downgraded high-skilled workers. In some circumstances, these additional downgraded high-skilled workers may even outnumber the high-skilled job destructions leading to a decrease in high-skilled unemployment. This change in the probability 
of finding a high-skilled job can induce a negative change in the number of low-skilled jobs when current equilibrium position is in the complementarity zone or a positive change in the alternative zone. The indirect effect on $p_{l}$ is positive or negative. We end up with three schematic situations that are presented in Figures 4, 5 and 6. In Figure 4, the substituability effect reinforces the consequences of the subsidy policy on the probability of finding a low-skilled position. On the contrary, in Figures 5 and 6 , the complementary effect plays against the subsidy policy. It reduces its effects in Figure 5 and can offset them in Figure 6 for some well-chosen parameter values. Unemployed high-skilled workers and re-entered low-skilled workers swell the ranks of people looking for a low-skilled position. This increases frictional unemployment on the low-skilled job market and affects more or less negatively the probability of finding a low-skilled position.

\section{An example: The French economy}

\subsection{Calibration}

As illustrated in the preceding section, in the set-up we have introduced, changes in low-skilled job subsidies can have very different consequences on the changes in low-skilled unemployment. They may reduce or increase it and when they reduce it, they can imply longer unemployment spells. In practice, it is of interest to determine in which situation we stand. We propose to illustrate this issue with a simple calibration in the case of the French economy.

Our model is characterized by a large number of parameters but cannot capture the complexity of institutions in a developed economy. The illustrative calibration exercise we carry out on French data likewise relies on an oversimplified representation of this economy and its institutions. In the sequel, we only consider jobs in market activities. The population under study is therefore composed of the working population minus civil servants plus those out of the working population who benefit from the minimum welfare payment given to those who are not entitled to unemployment benefit ("R.M.I"). We improperly use the expression "labor force" to refer to this population of 19.3 millions, 3.9 millions of unemployed people included ${ }^{9}$.

We are first led to raise the issue of the definition of skilled and unskilled persons. We cannot uniquely define these classes from the last academic degree got by the persons as in numerous situations (particularly for the older persons), there exists a gap between the last degree and the skills required to hold the position declared by the firms or the employees. Following Burnod and Chenu (2001), we consider as skilled employees, persons that hold a position in which is used his/her professional know-how acquired by educational or professional training. We thus construct our two classes on the basis of the professional position (or the last position for the unemployed ones) as described in Burnod and Chenu (2001) and the last degree, both declared in INSEE Employment Survey. If their last degree is a A-level or corresponds to a college training and they hold a high-skilled professional position, they are considered as high-skilled person. For those who are unemployed and have never worked, we only use the last academic degree. Unskilled persons are mainly unskilled workers and clerks (office clerks, sales clerks, janitors, night watchmen,...) without any degree or a degree less than a A-level. In 1998 according to INSEE Employment survey, they accounted for 36.2 of the labor force $\left(\phi_{l}=0.362\right)$. Based on this classification, the survey allows us to compute the rate of unemployment for each class and the share-out between high-skilled and low-skilled employment and unemployment, we get : $e_{h h}=0.547, e_{h l}=0.029$ and $e_{l l}=0.222, u_{h}=0.062$ and $u_{l}=0.139$. For sake of simplicity, we assume that voluntary unemployment is only composed of low-skilled persons, so that this last figure has to be broken down into voluntary $\left(u_{l, v}\right)$, classical $\left(u_{l, c}\right)$ and friction unemployment $\left(u_{l, f}\right)$. We assume that low-skilled productivities are distributed in $[0, \bar{s}]$ according to a $\operatorname{Beta}\left(a_{1}, a_{2}\right)$ distribution, where $a_{1}$ and $a_{2}$ are two real positive numbers. Depending on the values of these parameters, this distribution can have no mode or a mode between 0 and $\bar{s}$.

\footnotetext{
${ }^{9}$ Our definition of unemployed people doesn't match voluntarily the ILO's definition, in order to take into account the classic unemployed, which could be momentarily discouraged.
} 
Figure 4: Situation 1

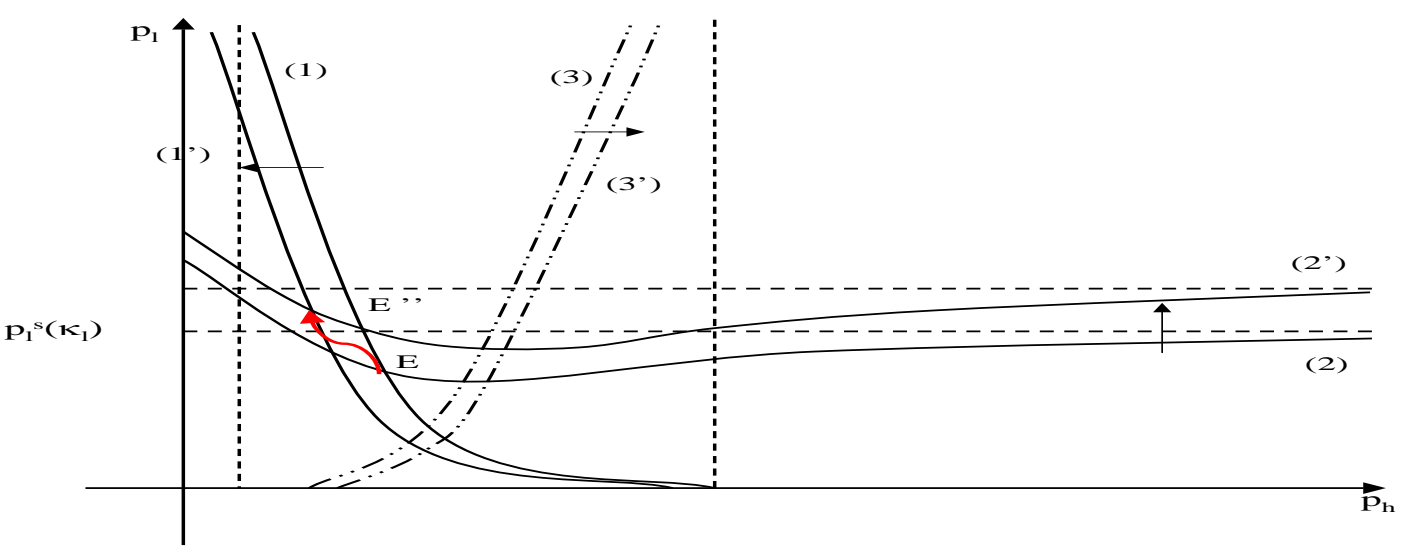

Figure 5: Situation 2

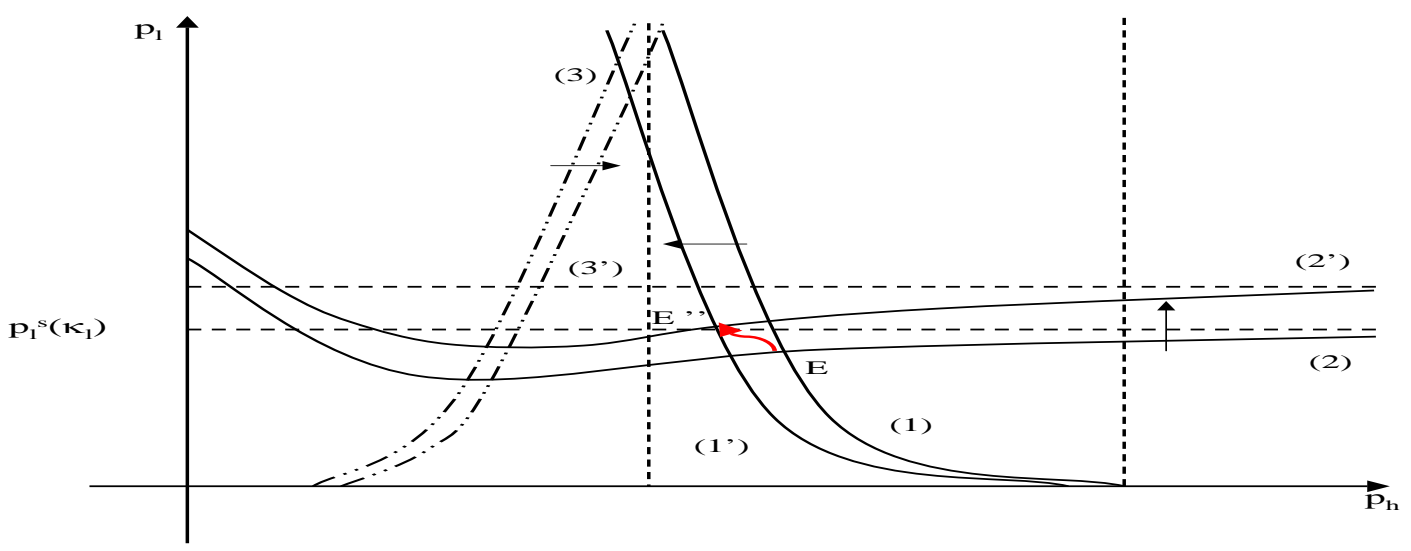

Figure 6: Situation 3

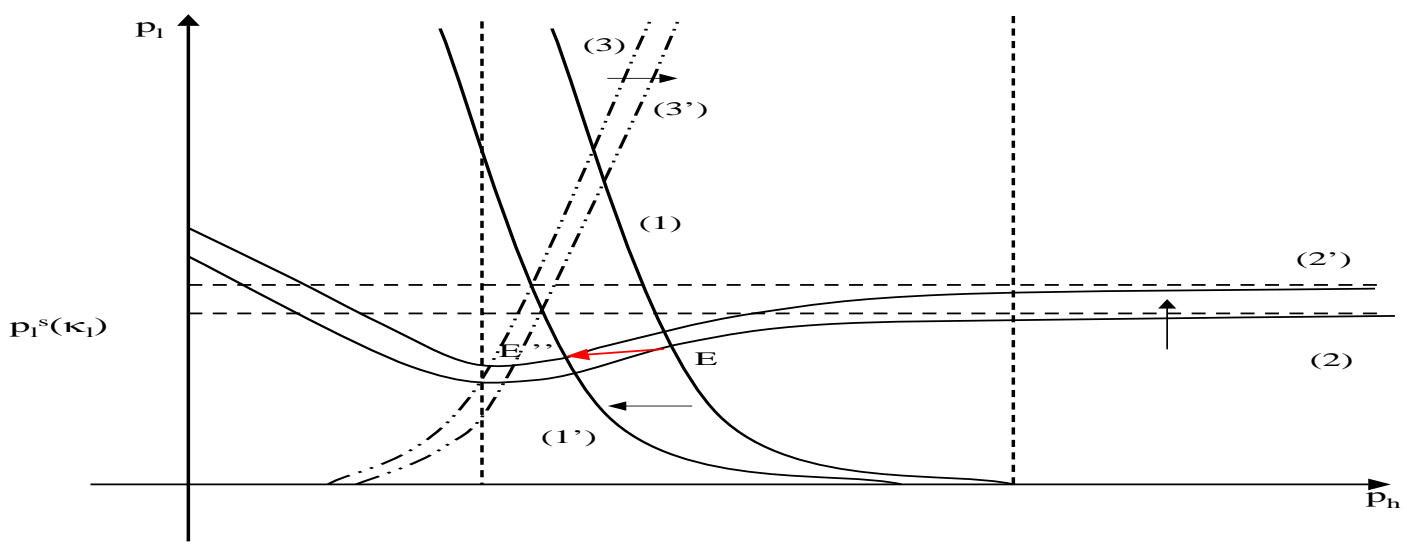


Table 1: Calibrated parameters

\begin{tabular}{|c|c|c|c|c|c|c|}
\hline \hline parameters & $\phi_{l}$ & $\beta$ & $r$ & $\sigma$ & $\delta_{h}$ & $\delta_{l}$ \\
\hline calibrated values & 0.362 & 0.25 & 0.05 & 0.5 & 0.1791 & 0.2341 \\
\hline parameters & $b$ & $\tau_{l}$ & $\tau_{h}$ & $\kappa_{l}$ & $G$ & $w_{h}$ \\
\hline calibrated values & 0.34 & 0.0227 & 0.143 & -0.0218 & 0.0098 & 1.39 \\
\hline \hline
\end{tabular}

\begin{tabular}{|c|c|c|c|c|c|c|c|}
\hline \hline parameters & $s_{h}$ & $\bar{s}$ & $a_{1}$ & $a_{2}$ & $m_{l}$ & $m_{h}$ & $u_{l, c}$ \\
\hline calibrated values & 1.7632 & 1.608 & 4.048 & 0.696 & 1.793 & 1.5133 & 0.0269 \\
\hline \hline
\end{tabular}

We then use administrative data sets (DADS) to measure the median monthly wage cost of lowskilled and high-skilled workers declared by firms. The above model focus on a limited number of questions. In particular, pension, health and family contributions and benefits are overlooked and there are not retirees and children. We keep to this simplified approach and consider that these contributions are equal to the benefits over a life-cycle. We present all the details of the calibration in Appendix C. Table 1 gives the values we end up with. For such a set of parameters, Figure 7 illustrates that there exists a unique mixed equilibrium. The distribution of low-skilled worker productivity is given in Figure 8. It is characterized by a mode in $\bar{s}$ and suggests a continuous distribution of productivities over low- and high-skilled workers.

From the calibration exercise, we first can notice that the probability of finding a job for lowskilled workers is closed to the lowest value. The frictional unemployment and then, the waiting time in unemployment is consequently very large for low-skilled people. There is then a large room for maneuver for fiscal policies in order to decrease the delay for finding a job. Moreover, the equilibrium is closed to the frontier between the substitution and complementarity zones, which affects the design of optimal labor market policies. When limiting our attention to equilibrium positions, a change in a fiscal instrument can have non monotonous effect on $p_{l}$ depending on the amplitude of the shift of the curves it implies. A small increase in $\tau_{h}$ may induce a decrease in the equilibrium value of $p_{l}$ but a larger one may have the opposite effect. Second, the simple-job-firm free-entry curve is flat around the equilibrium position. Large changes in the fiscal schemes are necessary to get a significant change in $p_{l}$.

\subsection{Study of low-skilled payroll tax cuts financed by an increase of tax burden on high-skilled labor}

\subsubsection{Empirical illustration}

From the calibration exercise, we conclude that we are in situation 2 (cf. Figure 5). A balanced low-skilled tax cut policy leads to a proportional small decrease of high-skilled job rate, and a more important increase of low-skilled job rate. It is interesting to note that as we are close to the frontier, such a policy may lead to a shift of the curve that entails a crossing in the substitution zone. In this zone, the favorable impact of this policy for low-skilled job rate is more accurate than in the complementarity one (cf. Figure 4).

In Figure 9, we illustrate the change in the equilibrium values when the low-skilled job subsidy is modified and the government budget is balanced by an appropriate increase in the high-skilled wage taxes, unemployment benefits are unchanged to not affect voluntary unemployment. In the first plot, we observe that the high-skilled wage tax rate decreases with $\kappa_{l}$, but additional computations show 
Figure 7: Equilibrium

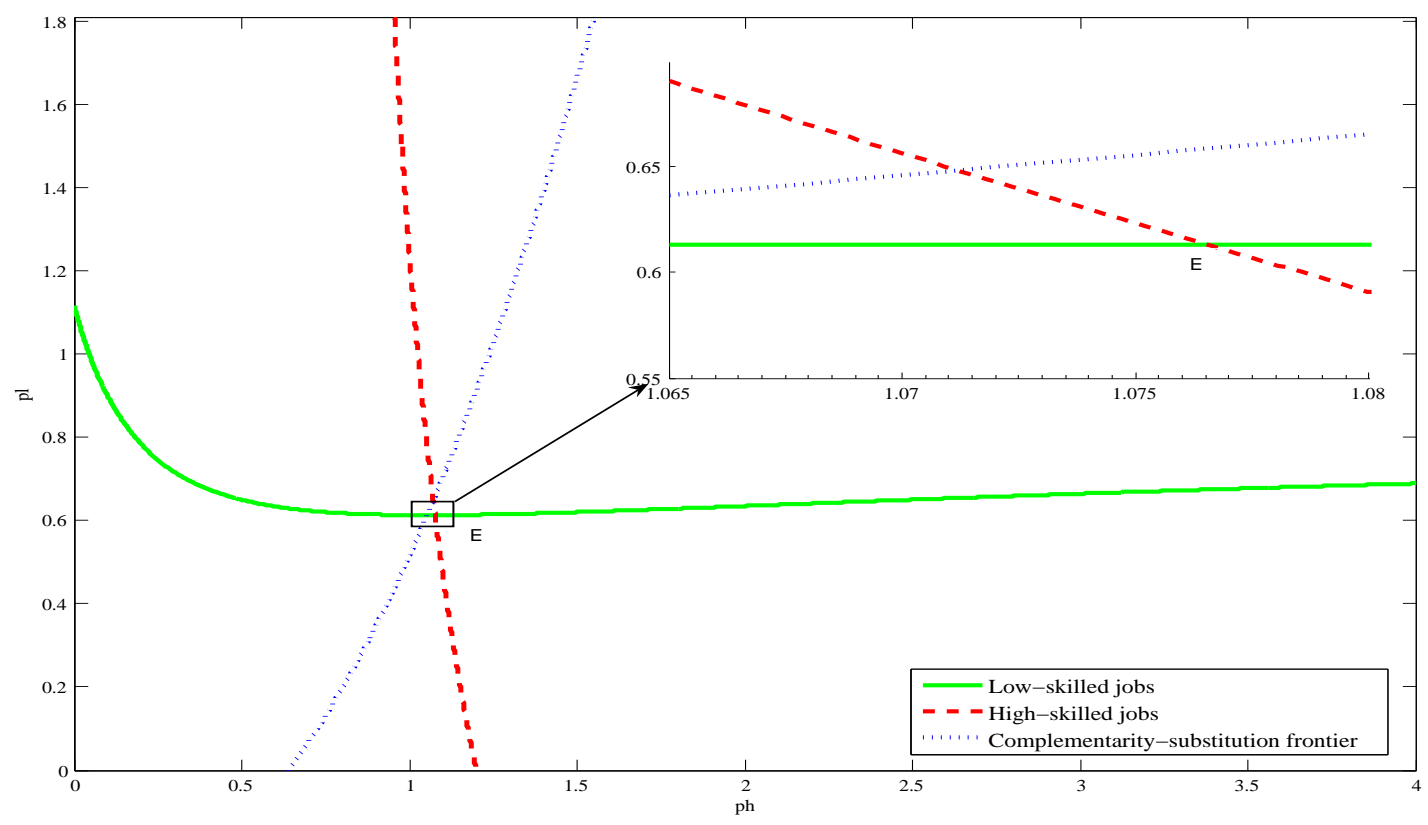

Figure 8: Low-skilled worker productivity distribution

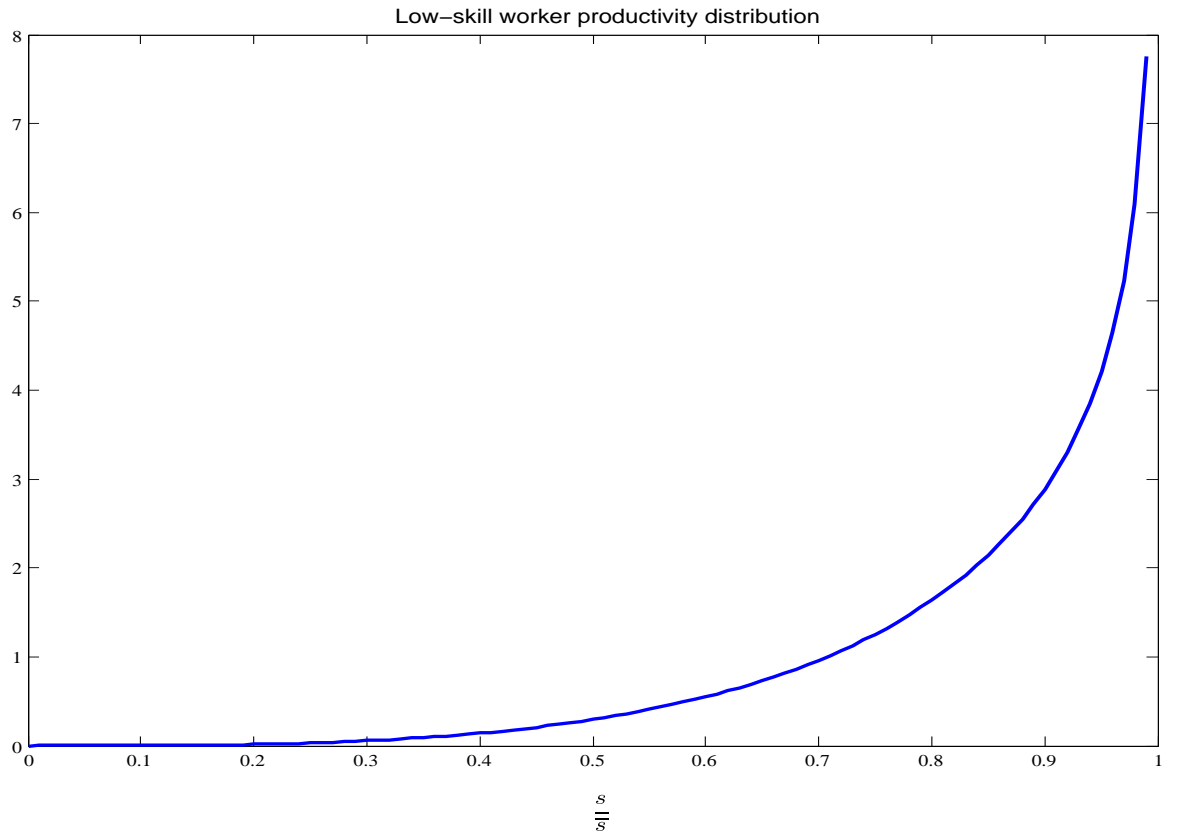


that for larger values of $\kappa_{l}$, it increases. When low-skilled jobs are significantly taxed, the implied increase in unemployment and associated unemployment benefits necessitates larger net taxes on highskilled workers. This echoes a "Laffer"-type property. When $\kappa$ decreases, low-skilled unemployment (classical and frictional) decreases and the number of downgraded high-skilled workers increases as due to higher net taxes on high-skilled jobs. This increase is nevertheless accompanied by a decreasing number of high-skilled unemployed, downgraded high-skilled workers outnumbering the high-skilled job destructions.

In presence of classical and frictional unemployment, the effects of low-skilled job subsidy policy get smaller as the subsidies increase. Classical unemployment is reduced and in our calibration exercise, frictional one decreases, but average productivity tends to decrease. The decreasing amplitude of consequences of low-skilled job subsidy policy is illustrated in Figures 10, 11 and 12.

Figure 10 illustrates that a $1 \%$ increase in subsidy is never self-financed by the implied decrease in unemployment benefits, but requires a larger and larger increase in high-skilled job tax to balance the budget. We can notice that this result is obtained despite that we observe a simultaneous reduction of high-skilled employment and high-skilled unemployment (Fig. 11).

As subsidies get larger, a marginal increase in subsidies induces a smaller decrease in classical unemployment and a larger increase in the number of downgraded high-skilled workers. This is illustrated in Figure 12 by the ratios of the marginal change in the number of downgraded high-skilled workers over, on the one hand, that in the number of low-skilled workers who leave classical unemployment and on the other hand, that in the number of low-skilled job creations. From our calibration, the level of subsidies in France induces an equilibrium in which any low-skilled worker reentering the job market is accompanied by 0.4 high-skilled worker accepting to be downgraded (Fig. 12). Similarly, we observe that the creation of four low-skilled jobs is accompanied by the downgrading of one high-skilled worker.

Shift of high-skilled workers to low-skilled jobs implies that equilibrium with minimum unemployment does not correspond to that induced by the maximization of an utilitarian criterion.

\subsubsection{Normative properties}

In order to evaluate simple-jobs subsidy policy, we consider the traditional utilitarian criterion, defined as the sum of individual utilities. Recalling that steady state intertemporal utility of an excluded worker is $b / r$, the utilitarian criterion writes

$$
\begin{aligned}
W= & \left(\phi_{l} X\left(\underline{\mathrm{w}}+\kappa_{l}\right)\right) \frac{b}{r}+\left(\int_{\underline{\mathrm{w}}+\kappa_{l}}^{\bar{s}} u_{l}(s) d s\right) U_{l}+u_{h} U_{h} \\
& +\left(\int_{\underline{\mathrm{w}}+\kappa_{l}}^{\bar{s}} e_{l l}(s) d s\right) N_{l l}+e_{h l} N_{h l}+e_{h h} N_{h h}
\end{aligned}
$$

Let us rewrite this equation in terms of flows of income:

$$
\begin{aligned}
r W= & \left(\phi_{l}+\phi_{h}\right) b+\phi_{l}\left(1-X\left(\underline{\mathrm{w}}+\kappa_{l}\right)\right)\left(r U_{l}-b\right)+\phi_{h}\left(r U_{h}-b\right) \\
& +\left(\int_{\underline{\mathrm{w}}+\kappa_{l}}^{\bar{s}} e_{l l}(s) d s\right) r\left(N_{l l}-U_{l}\right)+e_{h l} r\left(N_{h l}-U_{h}\right)+e_{h h} r\left(N_{h h}-U_{h}\right)
\end{aligned}
$$

and, from equations (8) and (9), we deduce

$$
\begin{aligned}
r W= & \left(\phi_{l}+\phi_{h}\right) b+\left[\phi_{l}\left(1-X\left(\underline{\mathrm{w}}+\kappa_{l}\right)\right) p_{l}+r \int_{\underline{\mathrm{w}}+\kappa_{l}}^{\bar{s}} e_{l l}(s) d s\right]\left(N_{l l}-U_{l}\right) \\
& +\left[\phi_{h}\left(p_{l}+p_{h}\right)+r\left(e_{h l}+e_{h h}\right)\right]\left(N_{h l}-U_{h}\right)+\left(\phi_{h} p_{h}+e_{h h} r\right)\left(N_{h h}-N_{h l}\right)
\end{aligned}
$$

At steady-state, $r W$ is the total flow of income distributed among workers. Equation (28) presents a decomposition of this total flow. The first term $\left(\phi_{l}+\phi_{h}\right) b$ represents the fact that anyone can expect to receive at least the minimum income $b$. The three other terms represent the expected flows of income that workers will receive as far as they are not excluded. First, there is the expected flow of 
Figure 9: Changes in equilibrium values with $\kappa$ when $b$ is given and $\tau_{h}$ ensures government budget balance
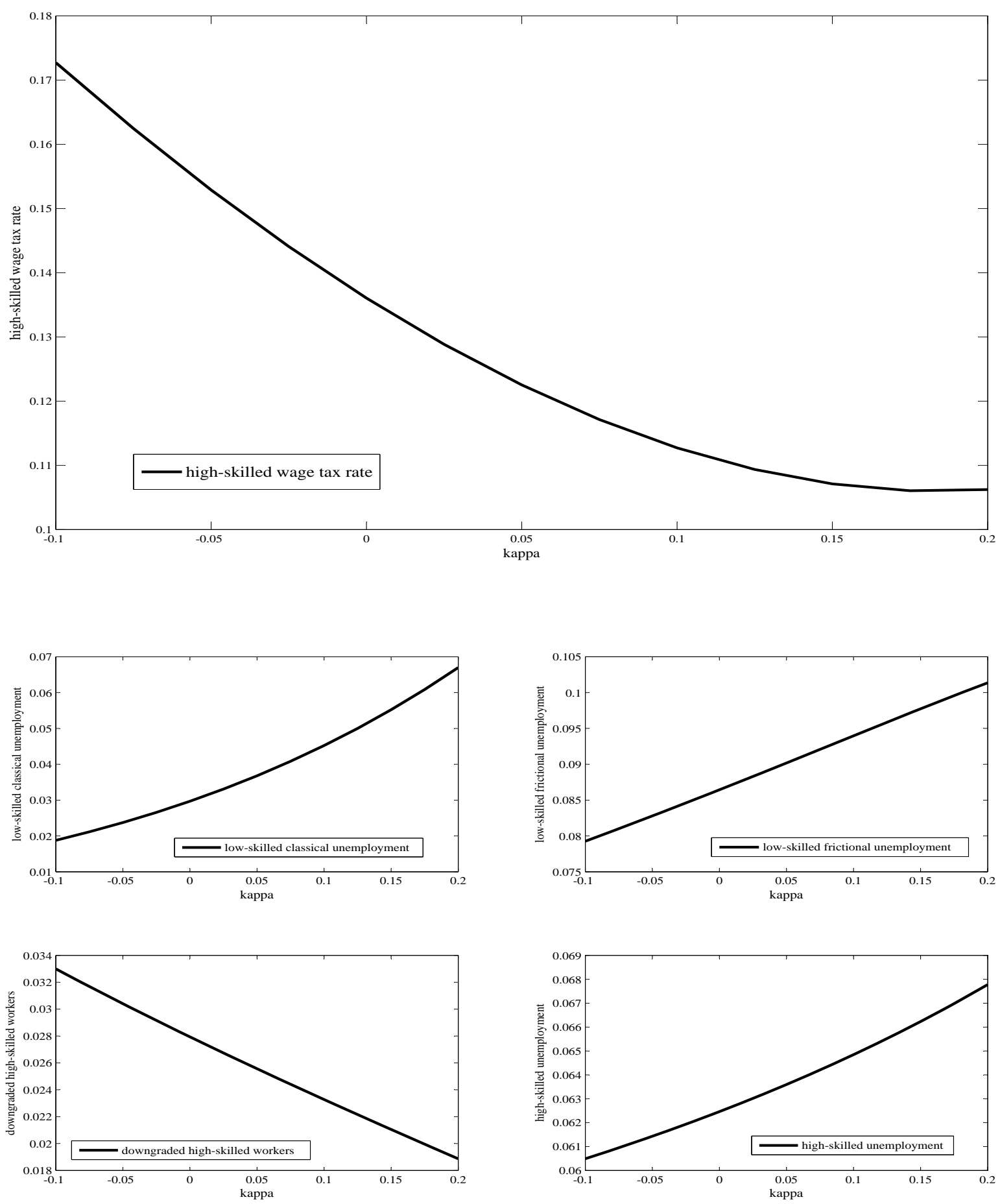
Figure 10: A marginal change in low-skilled job subsidies induces...

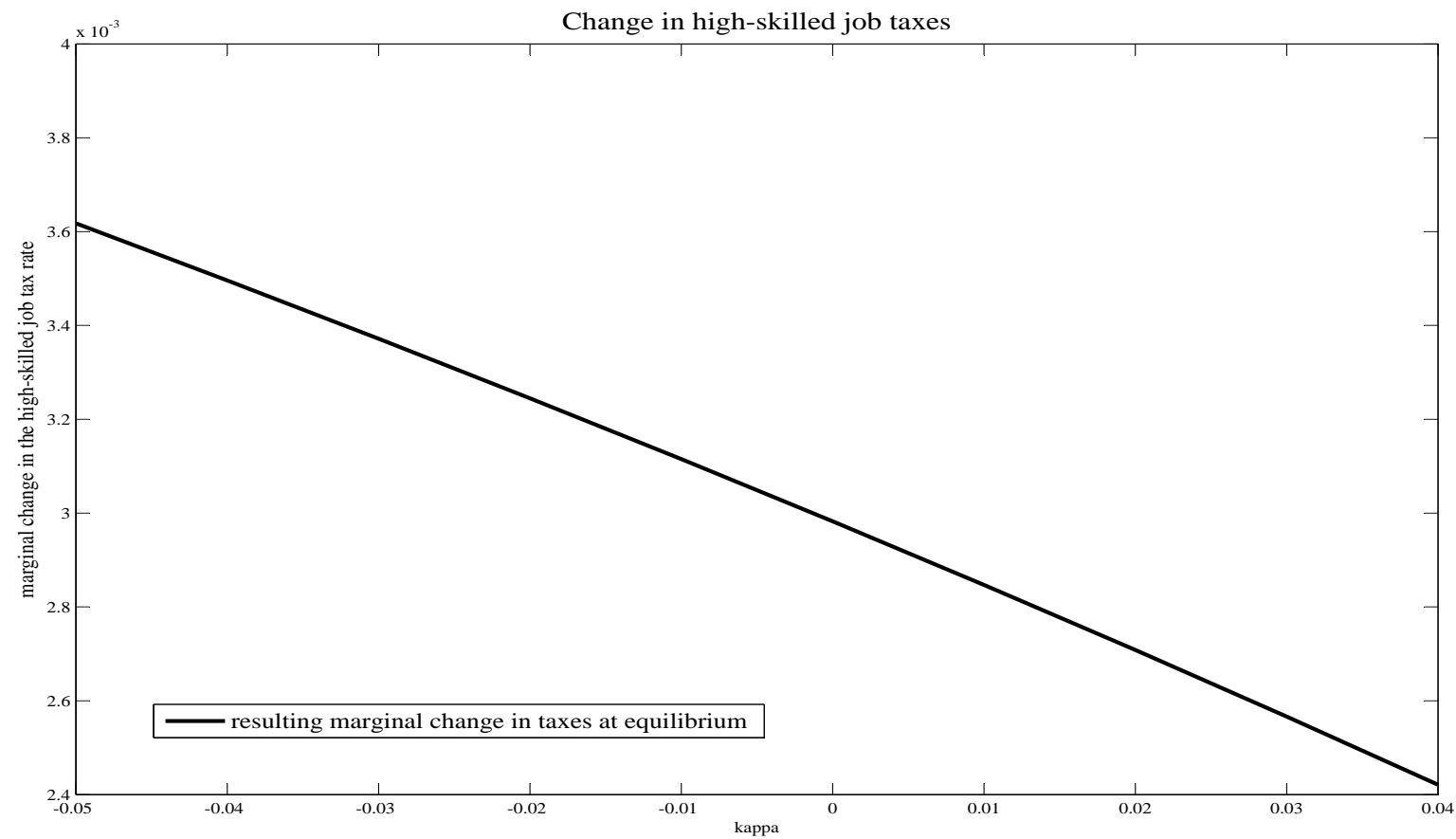

Figure 11: A marginal change in low-skilled job subsidies induces...

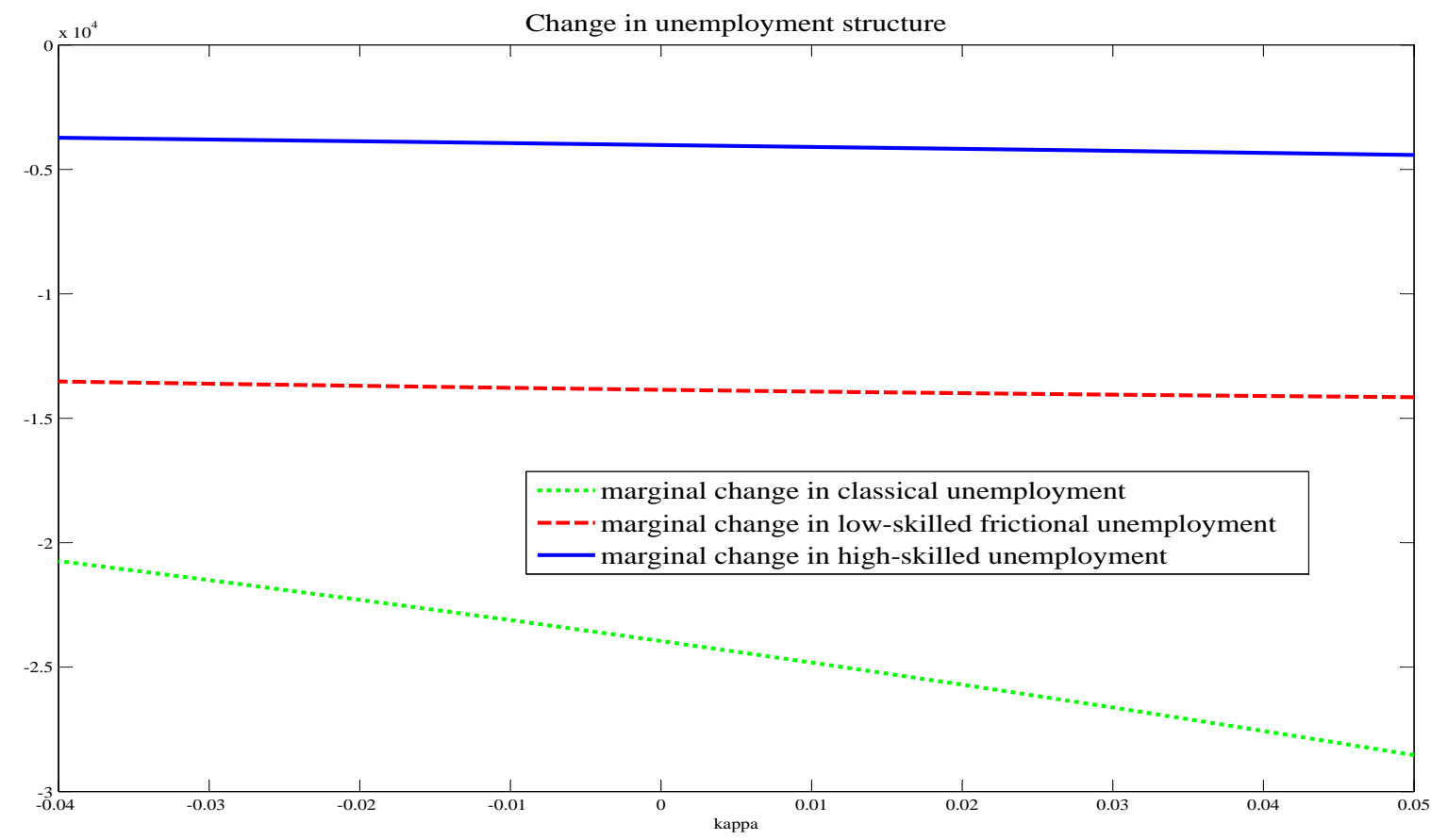


Figure 12: A marginal change in low-skilled job subsidies induces...

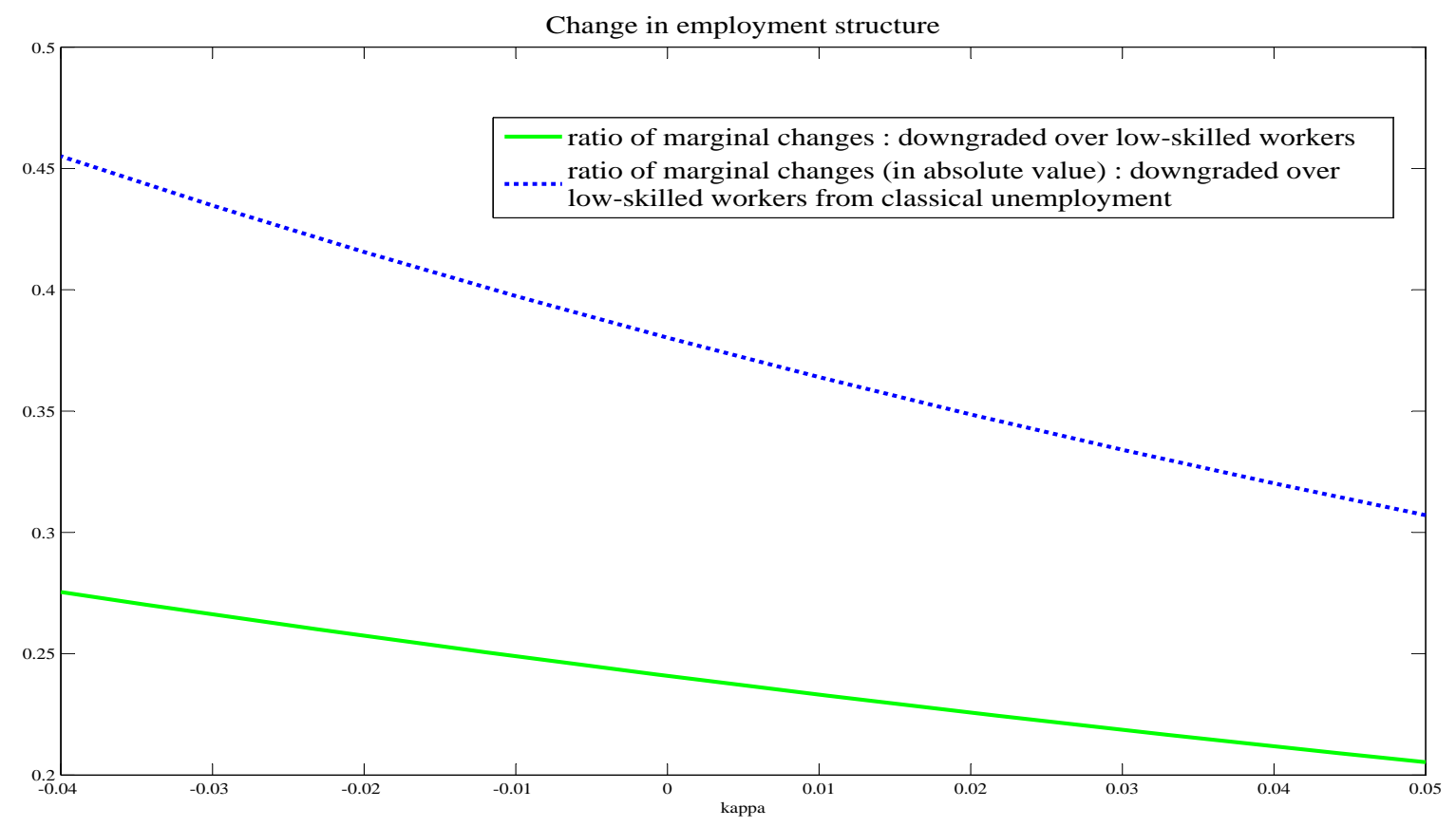

income for an unskilled worker to have a productivity parameter above $\underline{w}+\kappa_{l}$ and thus to have the opportunity to apply for a simple job. Of course this term is proportional to the difference $N_{l l}-U_{l}$ and will be positive as soon as $\tau_{l}+b<w$. Second, we have isolated the expected flow of income that a skilled worker enjoys at a cross-matching equilibrium since he can apply for simple jobs. This term is proportional to $N_{h l}-U_{h}$ and, here again, will be positive as soon as $\tau_{l}+b<\underline{w}$. Finally, skilled workers have also the opportunity to apply for complex jobs. This gives them an excepted flow of income represented by the term proportional to $N_{h h}-N_{h l}$ in equation (28). From the wage bargaining equation, one may deduce that

$$
N_{h h}-U_{h}=\frac{\beta}{1-\beta} J_{h h}=\frac{\beta}{1-\beta} \frac{c_{h}}{q_{h}}>0
$$

Thus, the presence of search frictions in the labor market forces the utility of high-skilled workers to be higher than high-skilled unemployed $\left(N_{h h}>U_{h}\right)$. This excludes that both equalities $N_{h h}=N_{h l}$ and $N_{h l}=U_{h}$ can be jointly satisfied.

These search frictions play different roles in the optimization of the various social optimum criteria we can consider for the instruments at the government disposal. This implies that the maximum of social surplus is associated to particular constraints on income distribution that limit the effects of redistributive policies.

Due to asymmetric information and frictions, the maximum in the Utilitarian objective function does not correspond to the minimum of unemployment (with $b$ fixed) as illustrated in Figure 13 (which is an enlarged picture of the above lower-right plot). In this Figure, we have plotted the variation of the total flow of income $r W$ with respect to the subsidy rate, keeping the unemployment benefit $b$ constant. The net lump-sum wage tax for high-skilled job is changed accordingly to balance the government budget. We have also drawn the relative importance of the different expected flow of income that a worker may expect according to his skill. We observe that the minimum of unemployment under incentive constraints (15) corresponds to the situation $N_{h l}=N_{h h}$, which is very different from the Utilitarian criterion. Implementing low-skilled job subsidy policy aims at reducing unemployment but it may induce some costs which move the equilibrium far away from the Utilitarian criterion. This 
Figure 13: Expected flows of income

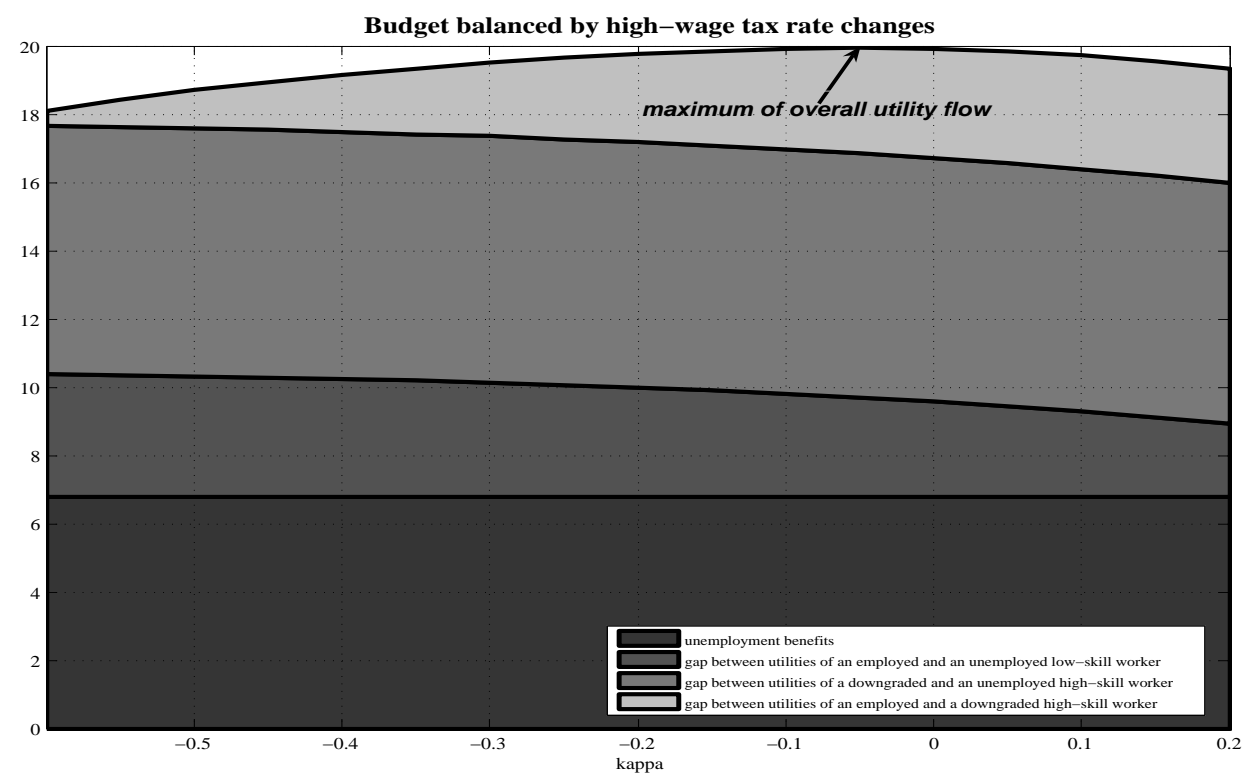

Table 2: Comparison of welfare levels

\begin{tabular}{|c|c|c|c|c|c|c|c|}
\hline \hline & $N_{l l}$ & $N_{h l}$ & $N_{h h}$ & $U_{l, c}$ & $U_{l, f}$ & $U_{h}$ & $W$ \\
\hline Calibrated values & 16.22 & 22.775 & 22.995 & 6.8 & 15.51 & 22.452 & 19.924 \\
\hline Unemployed minimization & 17.771 & 18.216 & 18.216 & 6.8 & 17.392 & 17.932 & 17.71 \\
\hline \hline
\end{tabular}

last one is maximum for a moderate low-skilled job subsidy, slightly larger in absolute value than the current one in France.

The comparison of the welfare levels for each type of situations between the calibrated situation and the minimum unemployment equilibrium in Table 2 shows that the second situation corresponds to a deterioration of unemployed high-skilled worker situations and an improvement of those of low-skilled persons out of classical unemployment. From a fiscal point of view, this corresponds to a large subsidy of low-skill jobs balanced by a large increase in net high-skilled wage taxes that reduces their return and their number. On the labor market, this corresponds to a reduction of job opportunities for highskilled people in low-skilled positions and a decrease in low-skilled person unemployment. Reducing their job opportunities implies a larger number of downgraded high-skilled workers that stay longer in these positions. This may affect the return of high-skilled degrees and create some disincentives to invest in higher education.

\subsection{Exogenous changes in the environment: A variation of productivity differen- tial}

In second simulation exercise, we illustrate the implied changes in the equilibrium parameters induced by an increase in the high-skilled productivity, the low-skilled productivity distribution remaining unchanged. This change corresponds to a productivity shock that favors high-skilled workers, it modifies all the equilibrium parameters and gives a room for maneuver to the government to change its subsidytax scheme. Keeping to our way of analyzing these issues, we do not consider a possible change in 
the unemployment benefits the government could implement since this measure could affect voluntary unemployment, but focus on the change in low-skilled job subsidies this productivity gain allows for. First we must notice that the consequences of a biased productivity shock depend on the nature of the relationship between low- and high-skilled job market. A higher value of $s_{h}$ induces a shift of the high-skilled job market curve in Figure 2 to the right. When the equilibrium is associated to a crossing of both curves in the decreasing part of the low-skilled job market one, a biased productivity shock implies a new equilibrium position with a larger number of high-skilled job positions and a reduced number of low-skilled job ones. The additional high-skilled wages tax the government can collect can be used to increase the low-skilled job subsidies. This reduces, but does not offset, the magnitude of this adverse change in the low-skilled job market. On the contrary, when the equilibrium corresponds to a crossing of both curves in the complement area, a biased productivity shocks is associated to an improvement in both low- and high-skilled job markets and a reduction in the frictional unemployment and the number of downgraded high-skilled workers, reinforced by the possible increase in low-skilled job subsidies that reduces the classical low-skilled unemployment.

\section{Conclusion}

In this paper, we provide a formal set-up to analyze the impact of low-skilled job subsidies policies on labour productivity. By introducing heterogeneous skills and possible downgrading of the high-skilled workers, we show that the effectiveness of such policies in reducing the classical unemployment are decreasing. In fact, any additional classical unemployed re-entering the job market is accompanied by an increasing number of downgraded high-skilled workers.

When the model is calibrated on French data, it is found that for five low-skilled workers leaving classical unemployment, two high-skilled workers are downgraded (although they might have been previously unemployed).

In our model, differences in productivity among workers are due to differences in their initial ability, but they can also be influenced by the unemployment duration, the type of job occupied and their career. Still, our model does not allow to analyze the impact of unemployment and downgrading on workers' skills accumulation. We provide a groundwork for future research comparing the effectiveness of training policies along the career with the ones based on low-skilled job subsidies. Importantly, as underlines also by Oskamp and Snower (2006), these two policies may affect initial educational choices since returns of schooling may change. 


\section{Appendices}

\subsection{Appendix A : List of symbols}

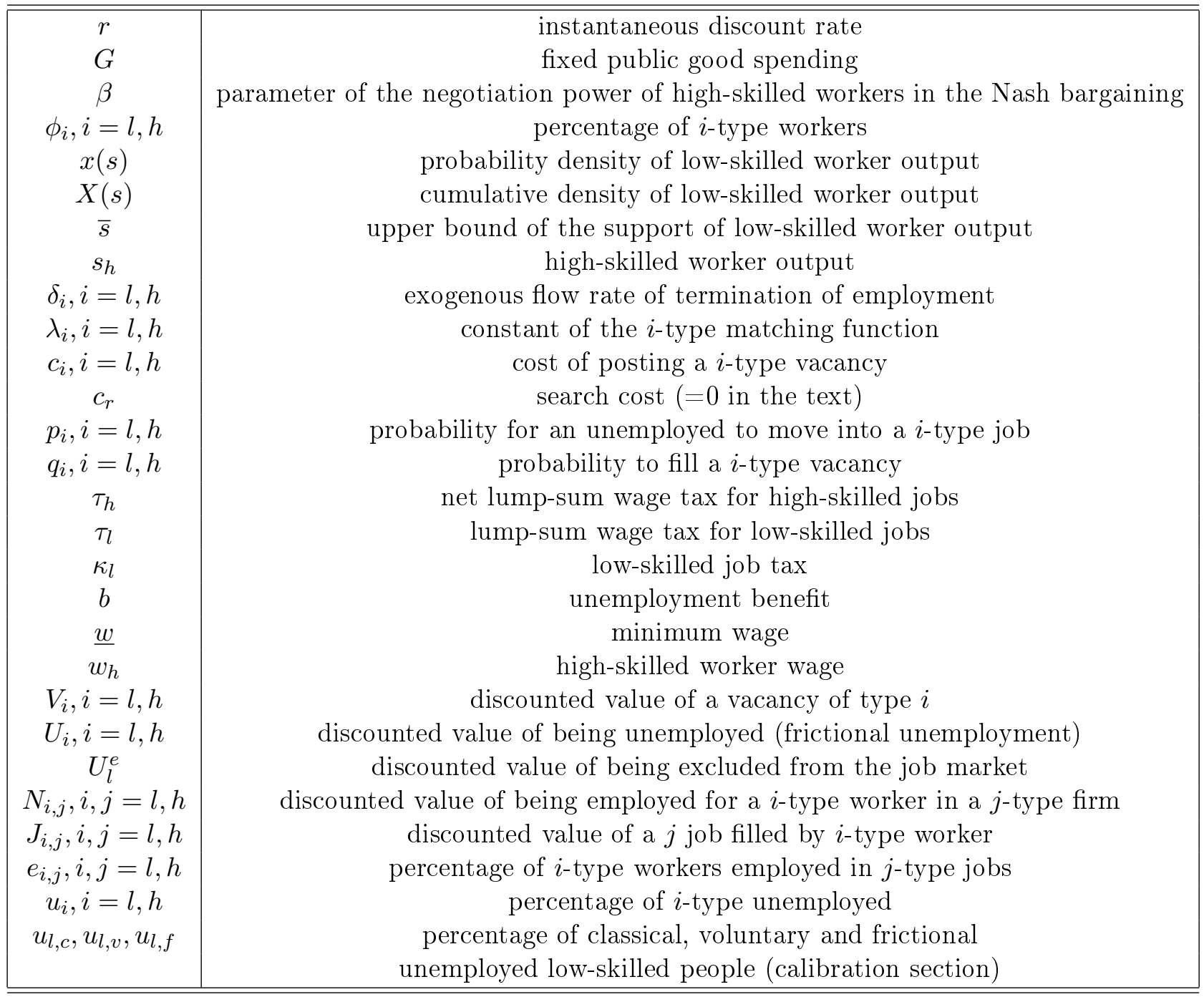

\subsection{Appendix B : Proofs}

\subsubsection{Unemployment and employment levels.}

At the cross-matching equilibrium satisfying inequalities (15), the flow equilibrium conditions for each state become:

$$
\begin{gathered}
p_{l} u_{h}=\left(p_{h}+\delta_{l}\right) e_{h l} \\
p_{l} u_{l}(s)=\delta_{l} e_{l l}(s) \\
p_{h}\left(u_{h}+e_{h l}\right)=\delta_{h} e_{h h}
\end{gathered}
$$

Then, we obtain

$$
\begin{gathered}
e_{l l}(s)=\frac{\phi_{l} x(s) p_{l}}{p_{l}+\delta_{l}}, \quad e_{h l}=\frac{\phi_{h} \delta_{h}}{p_{h}+\delta_{h}} \frac{p_{l}}{p_{l}+p_{h}+\delta_{l}}, \quad e_{h h}=\frac{\phi_{h} p_{h}}{p_{h}+\delta_{h}}, \\
u_{l}(s)=\frac{\phi_{l} x(s) \delta_{l}}{p_{l}+\delta_{l}}, \quad u_{h}=\frac{\phi_{h} \delta_{h}}{p_{h}+\delta_{h}} \frac{p_{h}+\delta_{l}}{p_{l}+p_{h}+\delta_{l}}
\end{gathered}
$$




\subsubsection{Interval $\left[\underline{p}_{h}, \bar{p}_{h}\right]$}

Proposition 1 states the range of values of the arrival rate $p_{h}$ that allow for positive arrival rates $p_{h}$ and $p_{l}$, and that satisfy incentives constraints $N_{h h} \geq N_{h l} \geq U_{h}$.

Let introduce the following notations

$$
\begin{gathered}
S_{l}=\underline{w}-\left(\tau_{l}+b\right) \\
S_{h}=s_{h}-\left(\tau_{h}+b\right)
\end{gathered}
$$

Three cases have to be considered

- $S_{h}-S_{l} \geq 0 \geq r+\delta_{h}-\beta\left(r+\delta_{l}\right)$ : the interval $\left[\underline{p}_{h}, \bar{p}_{h}\right]$ is defined by

$$
S_{h}-S_{l} \leq \frac{\left(r+\delta_{h}+\beta p_{h}\right) c_{h}}{(1-\beta) Q_{h}\left(p_{h}\right)} \leq S_{h}
$$

- $S_{h}-S_{l}<0$ and $r+\delta_{h}-\beta\left(r+\delta_{l}\right) \leq 0$ : then $\underline{p}_{h}$ and $\bar{p}_{h}$ are defined by

$$
\frac{\left(S_{h}-S_{l}\right)\left(r+\delta_{h}+\beta p_{h}\right)}{r+\delta_{h}-\beta\left(r+\delta_{l}\right)} \leq \frac{\left(r+\delta_{h}+\beta p_{h}\right) c_{h}}{(1-\beta) Q_{h}\left(p_{h}\right)} \leq S_{h}
$$

- $S_{h}-S_{l} \geq 0$ and $r+\delta_{h}-\beta\left(r+\delta_{l}\right)>0$ : then $\underline{p}_{h}$ and $\bar{p}_{h}$ are defined by

$$
S_{h}-S_{l} \leq \frac{\left(r+\delta_{h}+\beta p_{h}\right) c_{h}}{(1-\beta) Q_{h}\left(p_{h}\right)} \leq \min \left\{S_{h}, \frac{\left(S_{h}-S_{l}\right)\left(r+\delta_{h}+\beta p_{h}\right)}{r+\delta_{h}-\beta\left(r+\delta_{l}\right)}\right\}
$$

\subsubsection{Uniqueness of the steady-state equilibrium.}

Note first that uniqueness is trivial if $S_{l}=0$. Therefore, we focus on the case $S_{l}>0$. The free-entry condition for high-skilled jobs allows us to define function $P_{l}$

$$
p_{l}=P_{l}\left(p_{h}\right) \equiv\left(r+\delta_{l}+p_{h}\right) \frac{S_{h}-\left(r+\delta_{h}+\beta p_{h}\right) \frac{c_{h}}{(1-\beta) Q_{h}\left(p_{h}\right)}}{\left(r+\delta_{h}+\beta p_{h}\right) \frac{c_{h}}{(1-\beta) Q_{h}\left(p_{h}\right)}-\left(S_{h}-S_{l}\right)}
$$

The free-entry condition for simple jobs writes

$$
q_{l} \frac{B\left(\kappa_{l}\right)+\frac{r+\delta_{l}}{r+\delta_{l}+p_{h}} \gamma}{1+\gamma}=\frac{\left(r+\delta_{l}\right) c_{l}}{\bar{s}-\underline{w}-\kappa_{l}}
$$

where

Let us define

$$
\gamma=\Gamma\left(p_{h}\right) \equiv \frac{\phi_{h}}{\phi_{l}\left(1-X\left(\underline{w}+\kappa_{l}\right)\right)} \frac{\delta_{h}}{\delta_{l}} \frac{\delta_{l}+p_{h}}{\delta_{h}+p_{h}} \frac{\delta_{l}+P_{l}\left(p_{h}\right)}{\delta_{l}+P_{l}\left(p_{h}\right)+p_{h}} .
$$

$$
\tilde{H}\left(p_{h}\right) \equiv \frac{Q_{l}\left(P_{l}\left(p_{h}\right)\right)}{r+\delta_{l}+p_{h}} \frac{B\left(1+\frac{p_{h}}{r+\delta_{l}}\right)+\Gamma\left(p_{h}\right)}{1+\Gamma\left(p_{h}\right)}-\frac{c_{l}}{\bar{s}-\underline{w}-\kappa_{l}}
$$

Lemma 2 Let $B\left(\kappa_{l}\right)=1$. Assume there exists a cross-matching equilibrium. If

$$
\frac{d}{d p_{h}}\left(\frac{Q_{l}\left(P_{l}\left(p_{h}\right)\right)}{r+\delta_{l}+p_{h}}\right) \geq 0, \text { for } p_{h} \in\left[\underline{p}_{h}, \bar{p}_{h}\right]
$$

then this equilibrium is unique. A sufficient condition for the previous inequality to be satisfied is

$$
\left(\frac{-p_{l} Q_{l}^{\prime}\left(P_{l}\left(p_{h}\right)\right)}{Q_{l}\left(P_{l}\left(p_{h}\right)\right)}\right)\left(\frac{-p_{h} Q_{h}^{\prime}\left(p_{h}\right)}{Q_{h}\left(p_{h}\right)}\right)\left(1+\frac{r+\delta_{h}}{p_{h}}\right) \geq 1
$$


Proof. Since $\frac{d}{d p_{h}}\left(\frac{Q_{l}\left(P_{l}\left(p_{h}\right)\right)}{r+\delta_{l}+p_{h}}\right) \geq 0$ for $p_{h} \in I$, then $P_{l}^{\prime}$ is also negative on this interval. This implies that $\Gamma^{\prime}$ is also negative at the equilibrium value of the arrival rate $p_{h}$ and the result immediately follows.

Let now prove that (31) is a sufficient condition for uniqueness. The first-order derivative of $\frac{Q_{l}\left(P_{l}\left(p_{h}\right)\right)}{r+\delta_{l}+p_{h}}$ has the same sign as

$$
\frac{-1}{r+\delta_{l}+p_{h}}+\frac{Q_{l}^{\prime} P_{l}^{\prime}}{Q_{l}}=\frac{-1}{r+\delta_{l}+p_{h}}\left[1-\left(\frac{-p_{l} Q_{l}^{\prime}}{Q_{l}}\right)\left(\frac{-\left(r+\delta_{l}+p_{h}\right) P_{l}^{\prime}}{P_{l}}\right)\right]
$$

where

$$
\begin{aligned}
\frac{-\left(r+\delta_{l}+p_{h}\right) P_{l}^{\prime}}{P_{l}}=-1+\quad & \frac{\left(r+\delta_{l}+p_{h}\right)\left(1+\left(\frac{-p_{h} Q_{h}^{\prime}}{Q_{h}}\right)\left(1+\frac{r+\delta_{h}}{\beta p_{h}}\right)\right) \beta c_{h}}{(1-\beta) Q_{h}\left(p_{h}\right)} \\
& \times\left[\frac{1}{g\left(p_{h}\right)-\left(S_{h}-S_{l}\right)}+\frac{1}{S_{h}-g\left(p_{h}\right)}\right]
\end{aligned}
$$

and

$$
g\left(p_{h}\right) \equiv\left(r+\delta_{h}+\beta p_{h}\right) \frac{c_{h}}{(1-\beta) Q_{h}\left(p_{h}\right)} .
$$

Thus, the inequality $\frac{d}{d p_{h}}\left(\frac{Q_{l}\left(P_{l}\left(p_{h}\right)\right)}{r+\delta_{l}+p_{h}}\right) \geq 0$ is equivalent to

$$
\frac{\left(r+\delta_{l}+p_{h}\right) \beta c_{h}}{(1-\beta) Q_{h}\left(p_{h}\right)}\left[\frac{1}{g\left(p_{h}\right)-\left(S_{h}-S_{l}\right)}+\frac{1}{S_{h}-g\left(p_{h}\right)}\right] \geq \frac{1+\left(\frac{-p_{l} Q_{l}^{\prime}}{Q_{l}}\right)^{-1}}{1+\left(\frac{-p_{h} Q_{h}^{\prime}}{Q_{h}}\right)\left(1+\frac{r+\delta_{h}}{\beta p_{h}}\right)}
$$

From the inequality (18) in Proposition 1, we deduce

$$
g\left(p_{h}\right)-\left(S_{h}-S_{l}\right) \leq \frac{\left(r+\delta_{l}+p_{h}\right) \beta c_{h}}{(1-\beta) Q_{h}\left(p_{h}\right)}
$$

which implies that LHS in (32) is higher than

$$
\frac{S_{l}}{S_{h}-g\left(p_{h}\right)}
$$

which is greater than 1. Thus, (31) is a sufficient condition for $\frac{d}{d p_{h}}\left(\frac{Q_{l}\left(P_{l}\left(p_{h}\right)\right)}{r+\delta_{l}+p_{h}}\right) \geq 0$ to be satisfied.

\subsubsection{Analysis of $p_{l, l}^{c}\left(p_{h}\right)$ :}

Solutions of (26) are the roots of the following second order polynomial

$$
\left[1+b\left(p_{h}\right)\right] p_{l}^{2}+c\left(p_{h}\right) p_{l}+d\left(p_{h}\right)=0
$$

with

$$
\begin{aligned}
a\left(p_{h}\right) & =\frac{p_{l}^{s}\left(\kappa_{l}\right)}{B\left(\kappa_{l}\right)} \frac{r+\delta_{l}}{r+\delta_{l}+p_{h}} \\
b\left(p_{h}\right) & =\frac{\phi_{h} \delta_{h}\left(\delta_{l}+p_{h}\right)}{\left(1-X\left(\kappa_{l}+\underline{w}\right)\right) \phi_{l} \delta_{l}\left(\delta_{h}+p_{h}\right)} \\
c\left(p_{h}\right) & =\left(\delta_{l}+p_{h}\right)+\left[\delta_{l}-a\left(p_{h}\right)\right] b\left(p_{h}\right)-p_{l}^{s}\left(\kappa_{l}\right) \\
d\left(p_{h}\right) & =-a\left(p_{h}\right) b\left(p_{h}\right) \delta_{l}-p_{l}^{s}\left(\kappa_{l}\right)\left(\delta_{l}+p_{h}\right)
\end{aligned}
$$

For positive values of $p_{h}$, since $d\left(p_{h}\right)<0$, the discriminant $\Delta=c\left(p_{h}\right)^{2}-4\left[1+b\left(p_{h}\right)\right] d\left(p_{h}\right)$ is positive. The solutions have the following form

$$
p_{l, \pm}=\frac{-c\left(p_{h}\right) \pm \sqrt{c\left(p_{h}\right)^{2}-4 d\left(p_{h}\right)\left(1+b\left(p_{h}\right)\right)}}{2\left(1+b\left(p_{h}\right)\right)}
$$

Simple algebraic manipulations show that $p_{l,-}$ is negative, so we set $p_{l, l}^{c}\left(p_{h}\right)=p_{l,+}$. 


\subsection{Appendix C : Details of the calibration}

We detail the calibration procedure. We first present some parameter values we derived from already available statistics we picked in various works and then list the set of equations we used to calibrate the remaining parameters.

We decompose the wage cost into a labor contribution paid by the firm and by the employee and a remainder. In case of low-skilled worker, this remainder corresponds to $w_{l}$ that we set equal to 1 by convention $\left(w_{l}=\underline{w}=1\right)$. The labor market contribution paid by the employee is the unemployment benefit contribution that amounts to 0.0227 . For sake of simplicity, we assume that low-skilled workers do not paid direct income $\operatorname{tax}^{10}$, so that $\tau_{l}=0.0227$. The labor market contribution paid by employers is equal to the net sum of the unemployment benefit contribution and the subsidies on low-skilled jobs. We average this subsidy available for job paid between the minimum wage and 1.3 minimum wage we assume to be low-skilled position. This should lead to an over-evaluation as some high-skilled workers earn less than 1.3 minimum wage. We obtain that $\kappa_{l}=-0.0218$. Turning to high-skilled workers, a similar definition of the wage cost gives $w_{h}=1.39$. We then compute the amount of income tax paid on average by the $70 \%$ richest households that we add to the unemployment benefit contribution. This gives $\tau_{h}=0.143$. We then set $b$ equal to the monthly amount per capita paid by Social Security and the government by way of unemployment benefits and "R.M.I." benefits $: b=0.34$ and compute the "government budget" which gives us $G=0.0098$. Numerous empirical studies on the bargaining power of workers allow us to reasonably pick the value $\beta=0.25$. We set $r=0.05$ on a yearly basis.

From flow equilibrium conditions, we get :

$$
e_{h h}=\frac{p_{h} \phi_{h}}{\delta_{h}+p_{h}}
$$

and

$$
e_{h l}=\frac{\phi_{h} \delta_{h}}{p_{h}+\delta_{h}} \frac{p_{l}}{p_{l}+p_{h}+\delta_{l}}
$$

From Leclair and Roux (2004), we get the share $\left(P_{l s}=0.269\right)$ of low-skilled jobs and $\left(P_{h s}=0.164\right)$ of high-skilled jobs that last less than one year. In the steady state of our model, we have

$$
\begin{aligned}
P_{h s} & =1-e^{-\delta_{h}} \\
P_{l s} & =\left(1-e^{-\delta_{l}}\right) \frac{e_{l l}}{e_{l l}+e_{h l}}+\left(1-e^{-\left(\delta_{l}+p_{h}\right)}\right) \frac{e_{h l}}{e_{l l}+e_{h l}}
\end{aligned}
$$

Equation (35) gives $\delta_{h}=0.1791$ and then (33) $p_{h}=1.077$, it follows from (36) that $\delta_{l}=0.2341$ and from (34) that $p_{l}=0.6136$ which implies that $u_{l, f}=0.085$ and $u_{l, v}+u_{l, c}=0.055$.

The remaining deep parameters we have to calibrate are $\sigma, u_{l, c}, c_{h}, c_{l}, c_{r}, s_{h}, \bar{s}, a_{1}, a_{2}, \lambda_{h}$ and $\lambda_{l}$. We set $\sigma=0.5$ and consider a Cobb-Douglas matching function:

$$
m_{i}\left(\theta_{i}\right)=\lambda_{i}\left(\theta_{i}\right)^{1 / 2} \quad \text { for } i=l, h
$$

First, we notice that based on the set of available equations (free-entry and flow equilibrium conditions) and without additional information on vacancies, only $s_{h}, c_{h} / \lambda_{h}^{2}$ and $c_{l} / \lambda_{l}^{2}$ can be identified, which means that we have to calibrate seven parameters at most. Second, the cross-matching equilibrium we consider exists when inequalities (15) are satisfied, which induces numerous constraints on their values. Third, we have at our disposal two free-entry conditions (one for each job market), a wage bargaining equation, $e_{l l}$ equation

$$
\begin{aligned}
e_{l l} & =\frac{p_{l}\left(\phi_{l}-u_{l, v}\right)}{p_{l}+\delta_{l}}\left(1-X\left(\kappa_{l}+\underline{w}\right)\right) \\
& =\frac{p_{l}\left(\phi_{l}-u_{l, v}\right)}{p_{l}+\delta_{l}}\left(1-\operatorname{cdfbeta}\left(\frac{\kappa_{l}+\underline{w}}{\bar{s}}, a_{1}, a_{2}\right)\right)
\end{aligned}
$$

\footnotetext{
${ }^{10}$ About one half of French households do not pay income taxes.
} 
We therefore need additional information. Drawing on Crépon et al. (2002), we compute an estimate of the average ratio of productivity between a low-skilled job and a high-skilled job. This gives the ratio

$$
\begin{aligned}
\frac{\int_{\kappa_{l}+\underline{w}}^{\bar{s}} s\left(\frac{s}{\bar{s}}\right)^{a_{1}-1}\left(1-\frac{s}{\bar{s}}\right)^{a_{2}-1} \frac{d s}{\bar{s} B\left(a_{1}, a_{2}\right)}}{s_{h}} & =\frac{\bar{s} B\left(a_{1}+1, a_{2}\right)}{s_{h} B\left(a_{1}, a_{2}\right)}\left(1-\operatorname{cdfbeta}\left(\frac{\kappa_{l}+\underline{w}}{\bar{s}}, a_{1}+1, a_{2}\right)\right) \\
& =0.819
\end{aligned}
$$

Moreover, drawing on the various studies (Crépon and Deplatz (2001), Laroque and Salanié (2000)) on the job creations induced by the subsidies on low-skilled jobs implemented between 1992 and 1997 $\left(\Delta \kappa_{l}=-0.0756\right)$, we set that that this subsidy contributes to the creation of 450000 jobs. We then have six non-linear equations and three inequalities to determine the seven parameters $m_{l}, m_{h}, s_{h}, \bar{s}$, $u_{c, l}, a_{1}$ and $a_{2}$. Technically speaking, we still need additional information but at this stage the solution set might already be empty. The natural additional information might be given by vacancy statistics, but we did not find any usable statistic in this area. We then proceed as follows. Determining the sets of parameter values that satisfy the set of inequality constraints and the above equations, we observe that some of these sets are very small intervals. We then select the middle of the interval as the value of the parameter. We therefore proceed in a second step to a sensitivity analysis to the selected choice to analyze the robustness of our qualitative conclusions. 


\section{References}

Abbring, J. (1999). Commitment and wage bargaining in job matching models with costly search. Discussion paper, Tinbergen Institute, Amsterdam.

Acemoglu, D. (2001). Good jobs versus bad jobs. Journal of Labor Economics, 19:1-22.

Albrecht, J. and Vroman, S. (2002). A matching model with endogenous skill requirements. International Economic Review, 43:283-305.

Battu, H., Belfield, C., and Sloane, P. (2000). How well can we mesure graduate overeducation and its effects? National Institute Economic Review, 171:82-93.

Batyra, A. and Sneessens, H. (2006). Selective reductions in labour taxation: labour market adjustments and macroeconomic performance. mimeo, IRES, Louvain, Belgium.

Burnod, G. and Chenu, A. (2001). Employés qualifiés et non qualifiés: une proposition d'aménagement de la nomenclature des catégories socioprofessionnelles. Travail et Emploi, 48:87-105.

Cardullo, G. and Van der Linden, B. (2006). Employment subsidies and substitutable skills: An equilibrium matching approach. Discussion paper 2006-10, UCL, Louvain, Belgium.

Crépon, B., Deniau, N., and Perrez Duarte, S. (2002). Wages, productivity, and workers characteristics: A french perspective. mimeo, CREST.

Crépon, B. and Deplatz, R. (2001). Evolution des effets des dispositifs d'allègement de charges sur les bas salaires. Economie et Statistique.

Dolado, J., Jansen, M., and Jimeno, J. (2003). On-the-job search in a matching model with heterogenous jobs and workers. Discussion paper series 4094, CEPR.

Drèze, J. and Malinvaud, E. (1994). Growth and employment: The scope of a European initiative. European Economic Review, 38(3-4):489-504.

Gautier, P. (2002). Search externalities in a model with heterogeneous jobs and workers. Economica, pages $21-40$.

Hartog, J., Ridder, G., and Visser, M. (1994). Allocation of individuals to job levels under rationing. Journal of applied econometrics, 9:437-451.

Hungerbuhler, M., Lehmann, E., Parmentier, A., and Van der Linden, B. (2003). Optimal income taxation in an equilibrium unemployment model: Mirrlees meets pissarides. Mimeo, IRES, Université catholique de Louvain. Forthcoming in Review of Economic Studies.

Kleven, H. and Sorensen, P. (2004). Labour tax reform, the good jobs and the bad jobs. The Scandinavian Journal of Economics, 106(1):45-64.

Laroque, G. and Salanié, B. (2000). Une décomposition du non emploi en France. Economie et Statistiques, 331:47-67.

Leclair, M. and Roux, S. (2004). Mesure et utilisation des emplois instables dans les entreprises. Mimeo, INSEE.

Lommerud, K., Sandvik, B., and Straume, O. (2004). Good jobs, bad jobs and redistribution. Scandinavian Journal of Economics, 106:703-720.

Oskamp, F. and Snower, D. (2006). The effet of low-wage subsidies on skills and employment. Working Paper 1292, Kiel Institute for the World Economy, Kiel Germany. 
Pierrard, O. (2005). Impacts of selective reductions in labour taxation. Applied Economics Quaterly, $51(1)$.

Pierrard, O. and Sneessens, H. (2004). Low skill unemployment, biaised technological shocks and job competition. Discussion Paper 784, IZA.

Pissarides, C. (1985). Taxes, subsidies and equilibrium unemployment. Review of Economic Studies, LII:121-133.

Solow, R. (1990). The Labor Market as a Social Institution. The Royer Lectures.

Teulings, C. and Koopmanschap, M. (1989). An econometric model of crowding out of lower education levels. European Economic Review, 33:1653-64.

Wolinsky, A. (1987). Matching, search, and bargaining. Journal of Economic Theory, 42:311-333. 